\title{
Secondary Metabolites Produced by Combined Culture of Penicillium crustosum and a Xylaria sp.
}

Guihong Yu,${ }^{\dagger}$ Zichao Sun, ${ }^{\dagger}$ Jixing Peng,${ }^{\S}$ Meilin Zhu, ${ }^{\dagger}$ Qian Che,${ }^{\dagger}$ Guojian Zhang,,$\stackrel{\dagger}{\ddagger}$

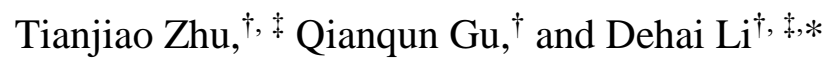

$\dagger$ Key Laboratory of Marine Drugs, Chinese Ministry of Education, School of Medicine and Pharmacy, Ocean University of China, Qingdao 266003, People's Republic of China

$\ddagger$ Laboratory for Marine Drugs and Bioproducts of Qingdao Pilot National Laboratory for Marine Science and Technology, Qingdao 266237, People's Republic of China

${ }^{\S}$ Key Laboratory of Testing and Evaluation for Aquatic Product Safety and Quality, Ministry of Agriculture and Rural Affairs, Yellow Sea Fisheries Research Institute, Chinese Academy of Fishery Sciences, Qingdao 266071, People's Republic of China 


\section{List of Supporting Information}

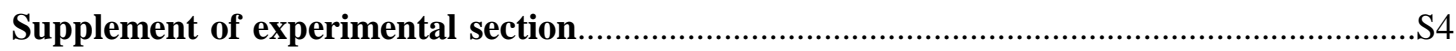

Table S1. ${ }^{1} \mathrm{H}(500 \mathrm{MHz})$ and ${ }^{13} \mathrm{C}(125 \mathrm{MHz})$ NMR data of compounds $\mathbf{1 a}$ and $\mathbf{1 b}$..........................S6

Figure S1. Key HMBC correlations of compounds 1a and 1b........................................ 7

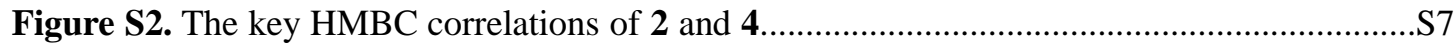

Figure S3. HPLC analysis of conversions of $\mathbf{2}$ to $\mathbf{1}$ and standard samples..................................S 8

Figure S4. UPLC-MS analysis of the $30^{\text {th }}$ day fermentation broth extracts (concentration: $5 \mathrm{mg} / \mathrm{mL}$; extracted negative ion peak of compounds 1-6) from co-cultivation Penicillium crustosum PRB-2 and Xylaria sp. HDN13-249, as well as culturing them alone

Figure S5. HPLC analysis of the $30^{\text {th }}$ day fermentation broth extracts (concentration: $5 \mathrm{mg} / \mathrm{mL}$, injection volume: $20 \mu \mathrm{L}$; UV detection wavelength: $274 \mathrm{~nm}$ ) from co-cultivation Penicillium crustosum PRB-2 and Xylaria sp. HDN13-249, as well as culturing them alone. $\mathrm{S} 10$

Figure S6. HPLC analysis of conversions of $\mathbf{6}$ to 5 and standard samples..................................S11

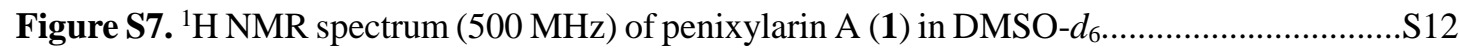

Figure S8. ${ }^{13} \mathrm{C}$ NMR spectrum $(125 \mathrm{MHz})$ of penixylarin A (1) in DMSO- $d_{6} \ldots \ldots \ldots \ldots \ldots \ldots . . . . . . . .212$

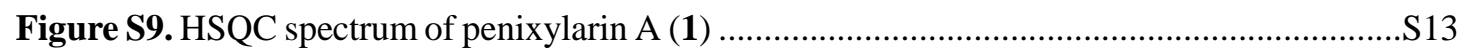

Figure S10. ${ }^{1} \mathrm{H}-{ }^{1} \mathrm{H}$ COSY spectrum of penixylarin A (1) .......................................................... 13

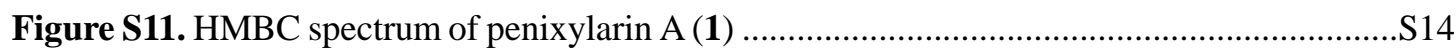

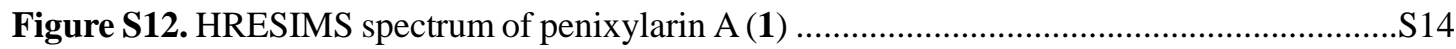

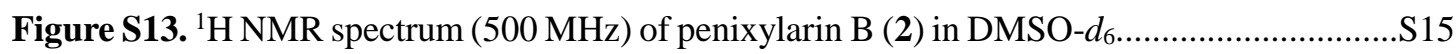

Figure S14. ${ }^{13} \mathrm{C}$ NMR spectrum (125 MHz) of penixylarin B (2) in DMSO- $d_{6} \ldots \ldots \ldots \ldots \ldots \ldots . . . . . . . .515$

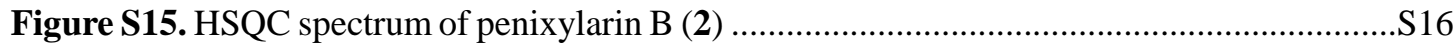

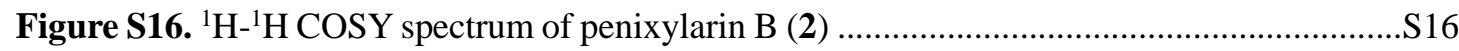

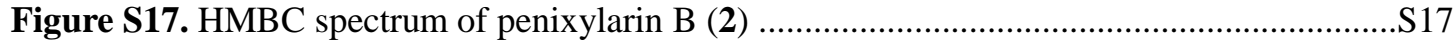

Figure S18. HRESIMS spectrum of penixylarin B (2) .......................................................... 17

Figure S19. ${ }^{1} \mathrm{H}$ NMR spectrum $(500 \mathrm{MHz})$ of penixylarin C (3) in DMSO- $d_{6} \ldots \ldots \ldots \ldots \ldots \ldots \ldots \ldots \ldots . . . . . . . . . . . . .18$

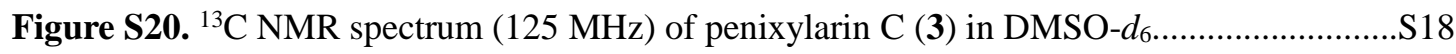

Figure S21. HSQC spectrum of penixylarin C (3) ………........................................................

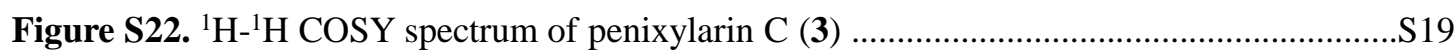

Figure S23. HMBC spectrum of penixylarin C (3) ……......................................................... 20 
Figure S24. HRESIMS spectrum of penixylarin C (3)

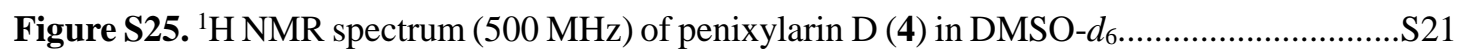

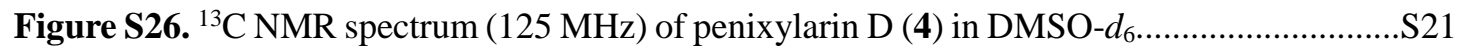

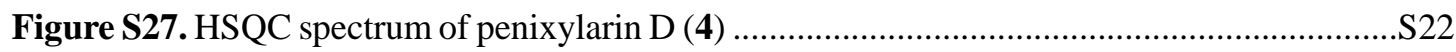

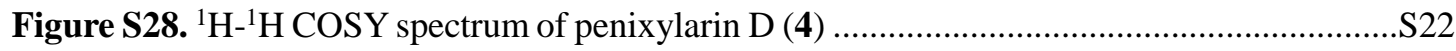

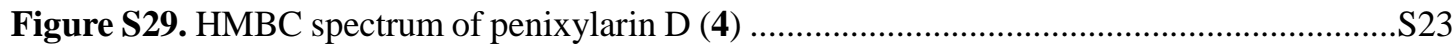

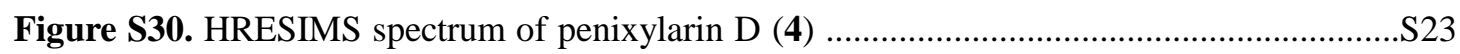

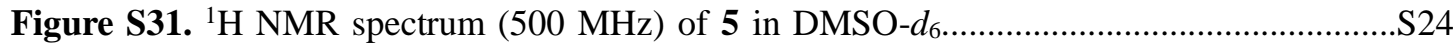

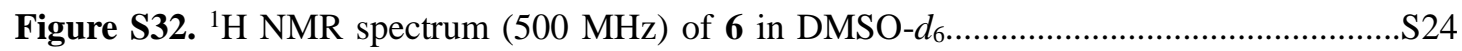

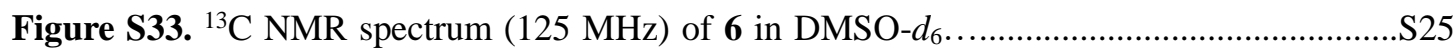

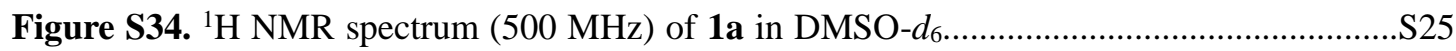

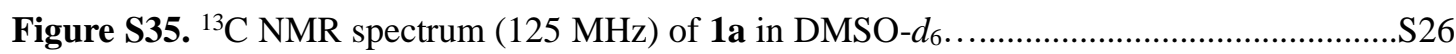

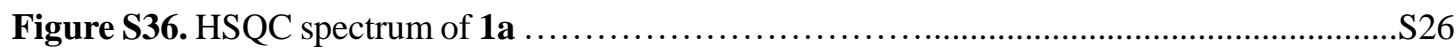

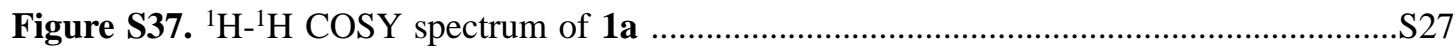

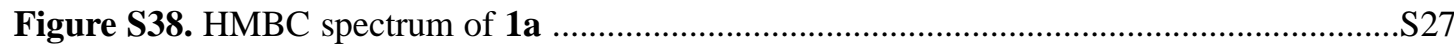

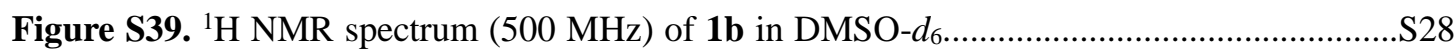

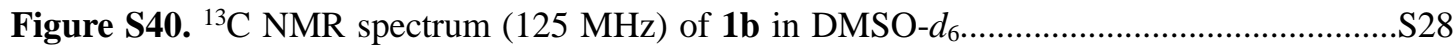

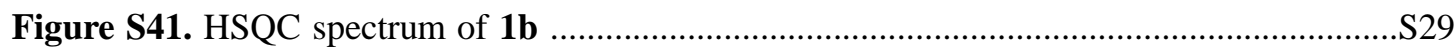

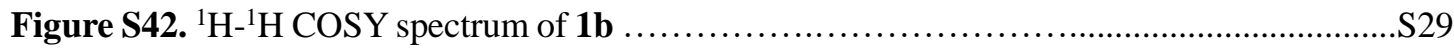

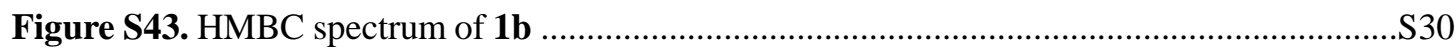




\section{Supplement of experimental section}

Additional characterization data for compounds 5 and 6: Compounds 5 and 6 were both isolated as pale yellow oils, with $[\mathrm{M}-\mathrm{H}]^{-} \mathrm{m} / z 363.3$ and 443.3 established by the ESIMS data, respectively. The 1D NMR spectra (Figure S32 and S33) of 6 indicated the presence of 3 nonprotonated carbons, three aromatic methines, one oxygenated methane $\left(\delta_{\mathrm{C}} 76.3, \delta_{\mathrm{H}} 4.00\right)$, one aryl-linked methylenes $\left(\delta_{\mathrm{C}} 35.7, \delta_{\mathrm{H}} 2.34\right)$, one methyl $\left(\delta_{\mathrm{C}} 14.4, \delta_{\mathrm{H}} 0.84\right)$, along with an alkyl side chain $\left(\delta_{\mathrm{H}} 1.0-1.5\right)$, which were the same to those observed in 1,3-dihydroxy-5-(12-sulfoxyheptadecyl)benzene. ${ }^{1}$ In addition, the ${ }^{1} \mathrm{H}$ NMR spectra (Figure S31) of compound 5 were also same to those observed in dihydroxy5-(12-hydroxyheptadecyl)benzene. ${ }^{1}$ Compound $\mathbf{6}$ could transform to compound 5 by losing the sulfonic $\mathrm{SO}_{3}$ group, which was consistent with the finding in the literature (Figure S6). ${ }^{1}$ Their absolute configurations were also deduced to be 12 "S based on biogenetic consideration. So, compounds 5 and $\mathbf{6}$ were determined to be dihydroxy-5-(12-hydroxyheptadecyl)benzene and 1,3dihydroxy-5-(12-sulfoxyheptadecyl)benzene, which was also supported by the ESIMS data.

Assay of Cytotoxicity Inhibitory Activity: Cytotoxic activities were evaluated using the HL-60, K562 cell lines by the MTT method and the BEL-7402, HCT-116, A549, HeLa, L-02, MGC-803, HO8910, SH-SY5Y, PC-3, MDA-MB-231 cell lines by the SRB method. In the MTT assay, the cell lines were grown in RPMI-1640 supplemented with 10\% FBS under a humidified atmosphere of 5\% $\mathrm{CO}_{2}$ and $95 \%$ air at $37^{\circ} \mathrm{C}$. Cell suspensions $(200 \mu \mathrm{L})$ at a density of $5 \times 10^{4}$ cells $/ \mathrm{mL}$ were plated in 96-well microtiter plates and incubated for $24 \mathrm{~h}$. The test compound solutions ( $2 \mu \mathrm{L}$ in DMSO) at $30 \mu \mathrm{M}$ were added to each well and further incubated for $72 \mathrm{~h}$ under the same conditions. MTT solution ( $20 \mu \mathrm{L}$ of a $5 \mathrm{mg} / \mathrm{mL}$ solution in IPMI-1640 medium) was added to each well and incubated for $4 \mathrm{~h}$. Old medium ( $150 \mu \mathrm{L})$ containing MTT was then gently replaced by DMSO and pipetted to dissolve any formazan crystals formed. Absorbance was then determined on a Spectra Max Plus plate reader at $540 \mathrm{~nm}$. In the SRB assay, cell suspensions $(200 \mu \mathrm{L})$ were plated in 96-cell plates at a density of $2 \times 10^{5}$ cells $/ \mathrm{mL}$. Then the test compound solutions ( $2 \mu \mathrm{L}$ in DMSO) at $30 \mu \mathrm{M}$ were added to each well and further incubated for $24 \mathrm{~h}$. Following drug exposure, the cells were fixed with $12 \%$ trichloroacetic acid and the cell layer was stained with $0.4 \%$ SRB. The absorbance of SRB solution was measured at $515 \mathrm{~nm} \cdot{ }^{2-4}$

Assay of Antimicrobial Activity: In the disk diffusion test, the paper discs with test compounds (25 $\mu \mathrm{g}$ per disc) were pasted on the PDA medium coated with P. crustosum PRB-2 and Xylaria sp., 
HDN13-249, respectively, with nystatin (5 $\mu$ g per disc) as positive drug. Incubated at $28{ }^{\circ} \mathrm{C}$ for 48 $\mathrm{h}$, and observed if there were inhibition zones. ${ }^{5}$ In the microdilution test, the microorganism suspension $\left(198 \mu \mathrm{L}, 10^{6} \mathrm{cfu} / \mathrm{mL}\right)$ in autoclaved growth medium (peptone $(20 \mathrm{~g} / \mathrm{L})$, beef extract $(3$ $\mathrm{g} / \mathrm{L}), \mathrm{NaCl}(5 \mathrm{~g} / \mathrm{L})$ for bacteria; peptone $(20 \mathrm{~g} / \mathrm{L})$, yeast extract $(10 \mathrm{~g} / \mathrm{L})$, glucose $(20 \mathrm{~g} / \mathrm{L})$ for Candida albicans) was added to each well of 96-well plates. Solutions ( $40 \mathrm{mM})$ of the compounds and positive drugs were made up in DMSO and dispensed into 96-well plates using the $2 \times$ microdilution method, to give 16 concentrations in the range of $200-0.006 \mu \mathrm{M}$. Incubated at $28{ }^{\circ} \mathrm{C}$ for $24 \mathrm{~h}$, and the lowest concentration that gave complete growth inhibition was recorded as the minimum inhibitory concentration (MIC) ${ }^{6}$

\section{References:}

(1) Kanoh, K.; Adachi, K.; Matsuda, S.; Shizuri, Y.; Yasumoto, K.; Kusumi, T.; Okumura, K.; Kirikae T. J. Antibiot. 2008, 61, 192-194.

(2) Mosmann, T. J. Immunol. Methods 1983, 65, 55-63.

(3) Skehan, P.; Storeng, R.; Scudiero, D.; Monks, A.; McMahon, J.; Vistica, D.; Warren, J. T.;

Bokesch, H.; Kenney, S.; Boyd, M. R. J. Natl. Cancer Inst. 1990, 82, 1107-1112.

(4) Du, L.; Zhu, T.; Liu, H.; Fang, Y.; Zhu, W.; Gu, Q. J. Nat. Prod. 2008, 71, 1837-1842.

(5) Andrews, J. M. J. Antimicrob. Chemother. 2001, 48 (Suppl 1), 43-57.

(6) Yu, G.; Wu, G.; Sun, Z.; Zhang, X.; Che, Q.; Gu, Q.; Zhu, T.; Li, D. Zhang, G. Mar. Drugs 2018, 16, 335 . 
Table S1. ${ }^{1} \mathrm{H}(500 \mathrm{MHz})$ and ${ }^{13} \mathrm{C}(125 \mathrm{MHz})$ NMR data of compounds 1a and $\mathbf{1 b}$ (DMSO- $d_{6}, \delta$ ppm)

\begin{tabular}{|c|c|c|c|c|}
\hline \multirow{2}{*}{ No. } & \multicolumn{2}{|r|}{$1 \mathbf{a}$} & \multicolumn{2}{|r|}{$1 \mathrm{~b}$} \\
\hline & $\delta_{\mathrm{c}}$, type & $\delta_{\mathrm{H}}(J$ in $\mathbf{H z})$ & $\delta \mathrm{c}$, type & $\delta_{\mathrm{H}}(J$ in $\mathrm{Hz})$ \\
\hline 1 & $154.6, \mathrm{C}$ & & $155.2, \mathrm{C}$ & \\
\hline 2 & $100.2, \mathrm{CH}$ & $6.23, \mathrm{~d}(2.4)$ & $100.5, \mathrm{CH}$ & $6.17, \mathrm{~s}$ \\
\hline 3 & $156.5, \mathrm{C}$ & & 156.5, C & \\
\hline 4 & 109.2, CH & 6.07, d (2.4) & $108.7, \mathrm{CH}$ & $6.05, \mathrm{~d}(2.3)$ \\
\hline 5 & $144.8, \mathrm{C}$ & & 144.7, C & \\
\hline 6 & $114.5, \mathrm{C}$ & & 115.1, C & \\
\hline $1^{\prime}$ & $17.7, \mathrm{CH}_{2}$ & $3.79, \mathrm{~s}$ & $17.8, \mathrm{CH}_{2}$ & $3.76, \mathrm{~s}$ \\
\hline $2^{\prime}$ & $113.9, \mathrm{C}$ & & 113.9, C & \\
\hline $3^{\prime}$ & $160.6, \mathrm{C}$ & & 160.9, C & \\
\hline $4^{\prime}$ & $112.4, \mathrm{C}$ & & 111.7, C & \\
\hline $5^{\prime}$ & $131.3, \mathrm{CH}$ & $7.54, \mathrm{~s}$ & $131.1, \mathrm{CH}$ & $7.50, \mathrm{~s}$ \\
\hline $6^{\prime}$ & $116.4, \mathrm{C}$ & & 116.4, C & \\
\hline $7^{\prime}$ & $161.5, \mathrm{C}$ & & 161.0, C & \\
\hline $8^{\prime}$ & 203.6, C & & 202.9, C & \\
\hline $9^{\prime}$ & 26.6, $\mathrm{CH}_{3}$ & $2.51, \mathrm{~s}$ & $26.4, \mathrm{CH}_{3}$ & $2.49, \mathrm{~s}$ \\
\hline $10^{\prime}$ & $16.3 \mathrm{CH}_{3}$ & $2.04, \mathrm{~s}$ & $16.4, \mathrm{CH}_{3}$ & $2.02, \mathrm{~s}$ \\
\hline $1^{\prime \prime}$ & $32.9, \mathrm{CH}_{2}$ & 2.49 , overlap & $32.9, \mathrm{CH}_{2}$ & $2.53, \mathrm{~m}$ \\
\hline $2^{\prime \prime}$ & $32.1, \mathrm{CH}_{2}$ & $0.95-1.25$, overlap & $32.1, \mathrm{CH}_{2}$ & $0.95-1.30$, overlap \\
\hline $3^{\prime \prime}$ & $29.7,{ }^{a} \mathrm{CH}_{2}$ & 0.95-1.25, overlap & $29.7,{ }^{b} \mathrm{CH}_{2}$ & $0.95-1.30$, overlap \\
\hline $4^{\prime \prime}$ & $29.5,{ }^{a} \mathrm{CH}_{2}$ & 0.95-1.25, overlap & $29.7,{ }^{b} \mathrm{CH}_{2}$ & $0.95-1.30$, overlap \\
\hline $5^{\prime \prime}$ & $29.4,{ }^{a} \mathrm{CH}_{2}$ & 0.95-1.25, overlap & $29.5,{ }^{b} \mathrm{CH}_{2}$ & $0.95-1.30$, overlap \\
\hline $6^{\prime \prime}$ & $29.4,{ }^{a} \mathrm{CH}_{2}$ & 0.95-1.25, overlap & $29.4,{ }^{b} \mathrm{CH}_{2}$ & $0.95-1.30$, overlap \\
\hline $7^{\prime \prime}$ & $29.3,{ }^{a} \mathrm{CH}_{2}$ & 0.95-1.25, overlap & $29.2,{ }^{b} \mathrm{CH}_{2}$ & $0.95-1.30$ overlap \\
\hline $8^{\prime \prime}$ & $29.3,{ }^{a} \mathrm{CH}_{2}$ & 0.95-1.25, overlap & $29.2,{ }^{b} \mathrm{CH}_{2}$ & $0.95-1.30$, overlap \\
\hline $9^{\prime \prime}$ & $29.1,{ }^{a} \mathrm{CH}_{2}$ & 0.95-1.25, overlap & $29.0,{ }^{b} \mathrm{CH}_{2}$ & $0.95-1.30$, overlap \\
\hline $10^{\prime \prime}$ & $25.2, \mathrm{CH}_{2}$ & 1.16 , overlap & $24.7, \mathrm{CH}_{2}$ & 0.85 , overlap \\
\hline $11^{\prime \prime}$ & $34.1, \mathrm{CH}_{2}$ & $1.46, \mathrm{~m}$ & $34.0, \mathrm{CH}_{2}$ & $1.34, \mathrm{~m}$ \\
\hline $12^{\prime \prime}$ & $74.6, \mathrm{CH}$ & $4.78, \mathrm{~m}$ & $74.6, \mathrm{CH}$ & $4.78, \mathrm{~m}$ \\
\hline $13^{\prime \prime}$ & $33.9, \mathrm{CH}_{2}$ & 1.33 , overlap & $34.1, \mathrm{CH}_{2}$ & $1.45, \mathrm{~m}$ \\
\hline $14^{\prime \prime}$ & $24.4, \mathrm{CH}_{2}$ & 0.85 , overlap & $24.8, \mathrm{CH}_{2}$ & 1.17 , overlap \\
\hline $15^{\prime \prime}$ & $31.3, \mathrm{CH}_{2}$ & 1.00 , overlap & $31.4, \mathrm{CH}_{2}$ & 1.18 , overlap \\
\hline $16^{\prime \prime}$ & $22.3, \mathrm{CH}_{2}$ & 1.05 , overlap & $22.4, \mathrm{CH}_{2}$ & 1.20 , overlap \\
\hline $17^{\prime \prime}$ & $14.4, \mathrm{CH}_{3}$ & $0.71, \mathrm{t}(7.2)$ & $14.3, \mathrm{CH}_{3}$ & $0.81, \mathrm{t}(6.9)$ \\
\hline $1^{\prime \prime \prime}$ & $170.6, \mathrm{C}$ & & 170.6, C & \\
\hline $2^{\prime \prime \prime}$ & $82.1, \mathrm{CH}$ & $4.84, \mathrm{~s}$ & $82.1, \mathrm{CH}$ & $4.85, \mathrm{~s}$ \\
\hline $3^{\prime \prime \prime}$ & 137.2, C & & 137.3, C & \\
\hline $4^{\prime \prime \prime}$ & $127.5, \mathrm{CH}$ & 7.20-2.40, overlap & $127.4, \mathrm{CH}$ & 7.20-2.40, overlap \\
\hline $5^{\prime \prime \prime}$ & $128.8, \mathrm{CH}$ & 7.20-2.40, overlap & $128.7, \mathrm{CH}$ & 7.20-2.40, overlap \\
\hline $6^{\prime \prime \prime}$ & $127.5, \mathrm{CH}$ & 7.20-2.40, overlap & $127.4, \mathrm{CH}$ & 7.20-2.40, overlap \\
\hline $7^{\prime \prime \prime}$ & $128.8, \mathrm{CH}$ & $7.20-2.40$, overlap & $128.7, \mathrm{CH}$ & $7.20-2.40$, overlap \\
\hline $8^{\prime \prime \prime}$ & $128.8, \mathrm{CH}$ & 7.20-2.40, overlap & $128.9, \mathrm{CH}$ & 7.20-2.40, overlap \\
\hline $9^{\prime \prime \prime}$ & $57.1, \mathrm{CH}_{3}$ & $3.29, \mathrm{~s}$ & $57.1, \mathrm{CH}_{3}$ & $3.30, \mathrm{~s}$ \\
\hline
\end{tabular}




\begin{tabular}{ccc}
$3-\mathrm{OH}$ & $9.11, \mathrm{~s}$ & $8.98, \mathrm{~s}$ \\
$3^{\prime}-\mathrm{OH}$ & $13.41, \mathrm{~s}$ & $13.48, \mathrm{~s}$ \\
\hline${ }^{,} b$ : interchangeable &
\end{tabular}

Figure S1. Key HMBC correlations of compounds $\mathbf{1 a}$ and $\mathbf{1 b}$
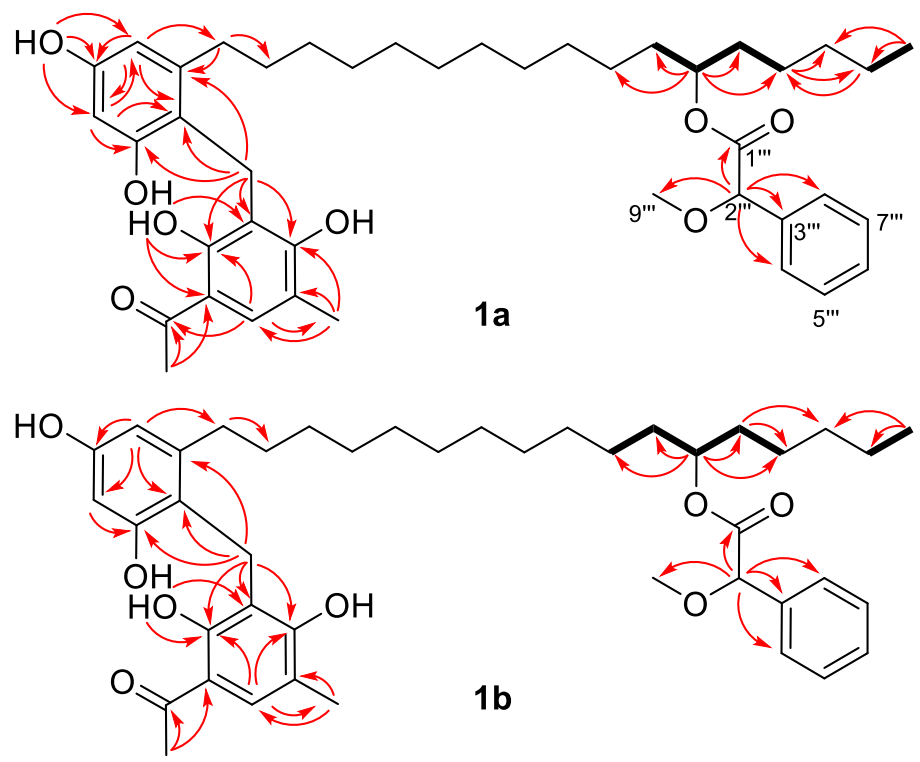

Figure S2. The key HMBC correlations of 2 and 4.
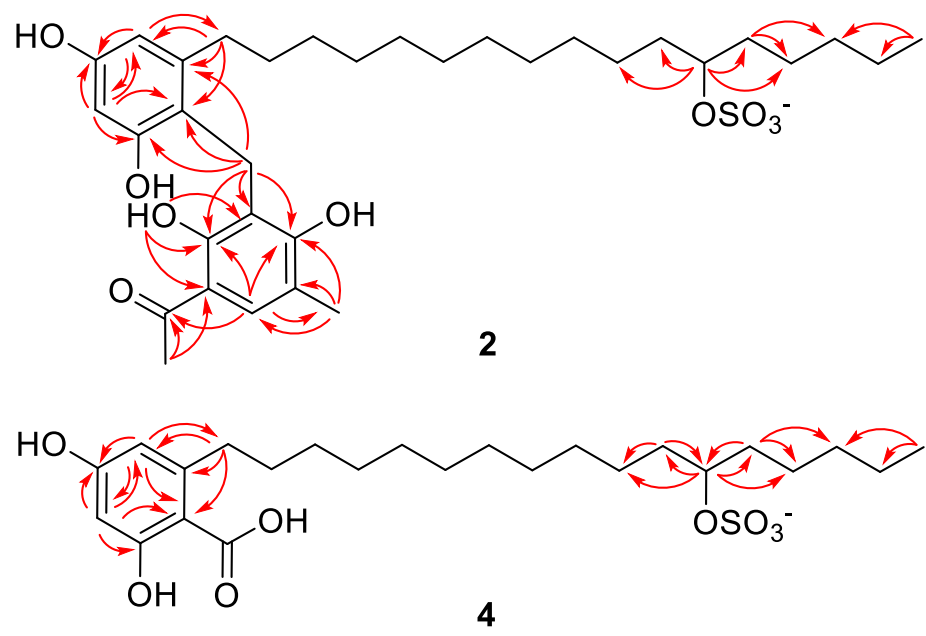
Figure S3. HPLC analysis of conversions of $\mathbf{2}$ to $\mathbf{1}$ and standard samples.
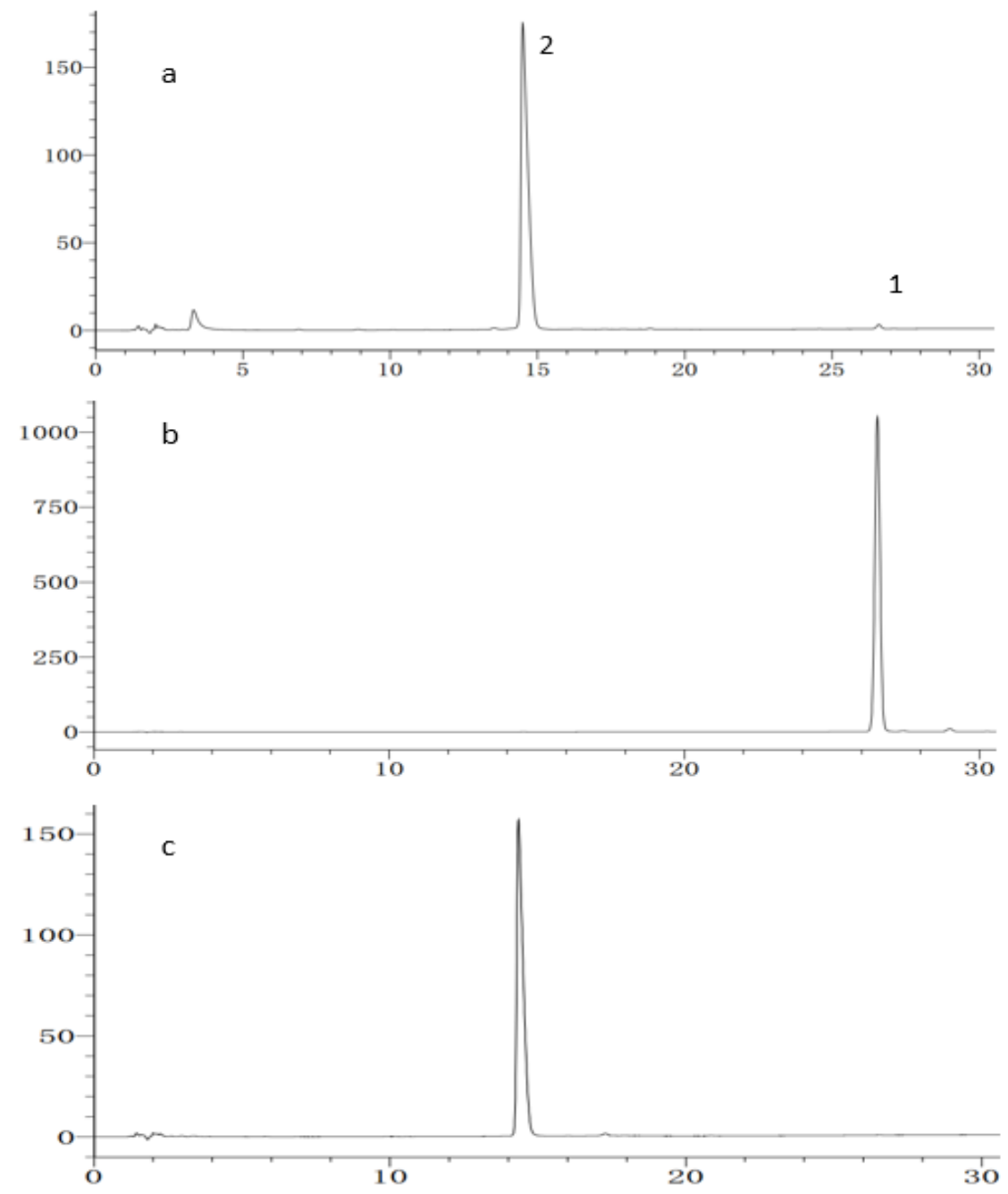

Note: a: conversion of $\mathbf{2}$ to $\mathbf{1}$ in $\mathrm{MeOH}$ after 8 days; b: standard sample of $\mathbf{1}$; c: standard sample of 2. The data were collected by HPLC $\left(280 \mathrm{~nm}\right.$ ) with $\mathrm{CH}_{3} \mathrm{CN}$ and water (with $2 / 1000$ trifluoroacetic acid) (0-2 min: 50:50, 2-30 min: from 50:50 to 100:0). 
Figure S4. UPLC-MS analysis of the $30^{\text {th }}$ day fermentation broth extracts (concentration: $5 \mathrm{mg} / \mathrm{mL}$; extracted negative ion peak of compounds 1-6) from co-cultivation Penicillium crustosum PRB-2 and Xylaria sp. HDN13-249, as well as culturing them alone.

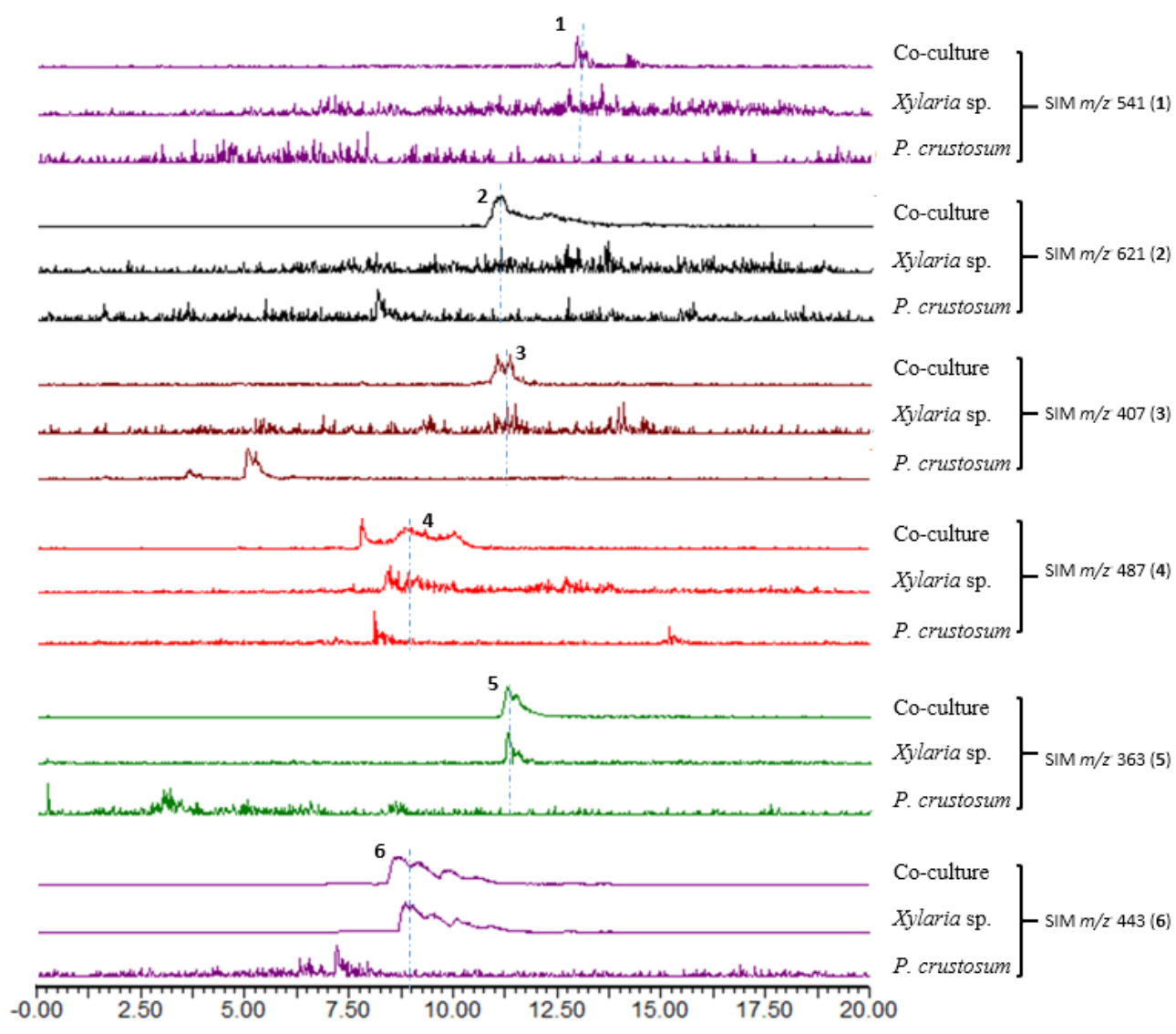

Analysis method: $\mathrm{CH}_{3} \mathrm{CN}$ (with 1/1000 formic acid) and water (with 1/1000 formic acid) (0-15 min: 5:95-95:5, 15-17: 95:5, 17-18 min: 95:5-100:0, 18.1-20 min: 5:95). 
Figure S5. HPLC analysis of the $30^{\text {th }}$ day fermentation broth extracts (concentration: $5 \mathrm{mg} / \mathrm{mL}$, injection volume: $20 \mu \mathrm{L}$; UV detection wavelength: $274 \mathrm{~nm}$ ) from co-cultivation Penicillium crustosum PRB-2 and Xylaria sp. HDN13-249, as well as culturing them alone.

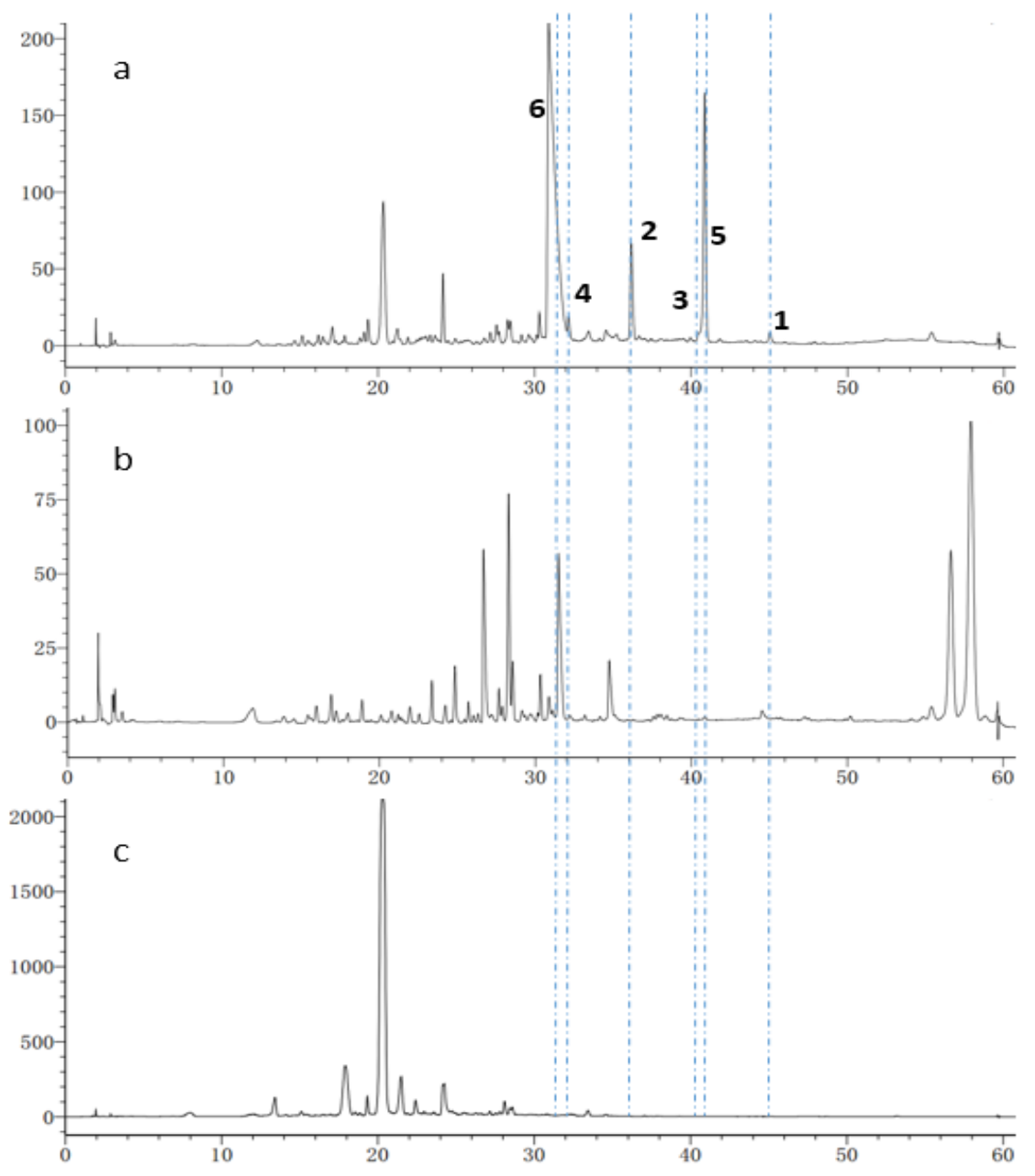

Note: a: co-cultivation; b: culturing Xylaria sp. HDN13-249 alone; c: culturing Penicillium crustosum PRB-2 alone. Analysis method: $\mathrm{CH}_{3} \mathrm{CN}$ and water (with 2/1000 trifluoroacetic acid) (05 min: 5:95, 5-45 min: 5:95 to 100:0, 45-55 min: 100:0, 55.1-60 $\min : 5: 95)$. 
Figure S6. HPLC analysis of conversions of $\mathbf{6}$ to $\mathbf{5}$ and standard samples.
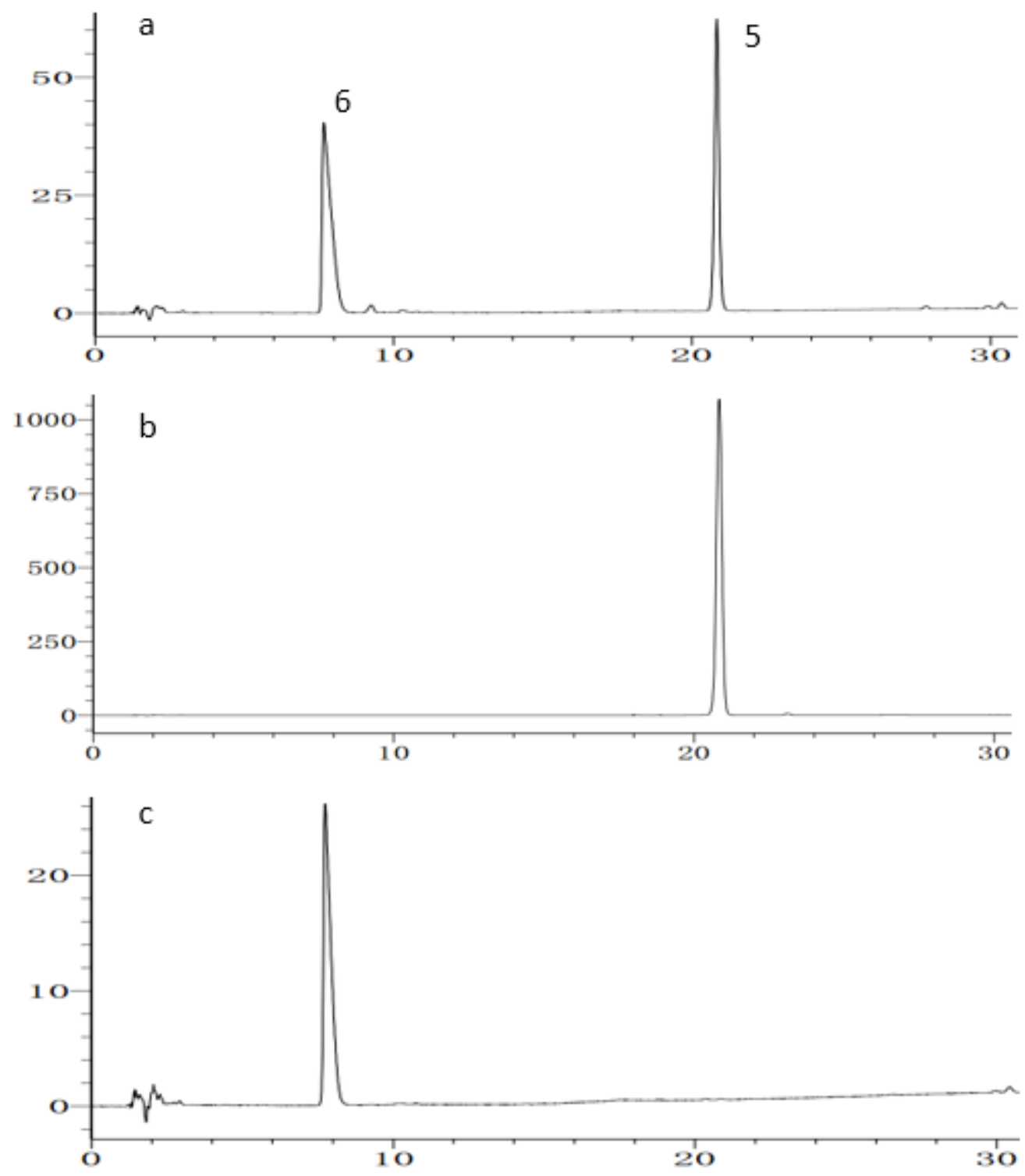

Note: a: conversion of $\mathbf{6}$ to 5 in $\mathrm{MeOH}$ after 8 days; b: standard sample of $\mathbf{5}$; $\mathrm{c}$ : standard sample of 6. The data were collected by HPLC $(275 \mathrm{~nm})$ with $\mathrm{CH}_{3} \mathrm{CN}$ and water (with $2 / 1000$ trifluoroacetic acid) (0-2 min: 50:50, 2-30 min: from 50:50 to 100:0). 
Figure S7. ${ }^{1} \mathrm{H}$ NMR spectrum $(500 \mathrm{MHz})$ of penixylarin A (1) in DMSO- $d_{6}$

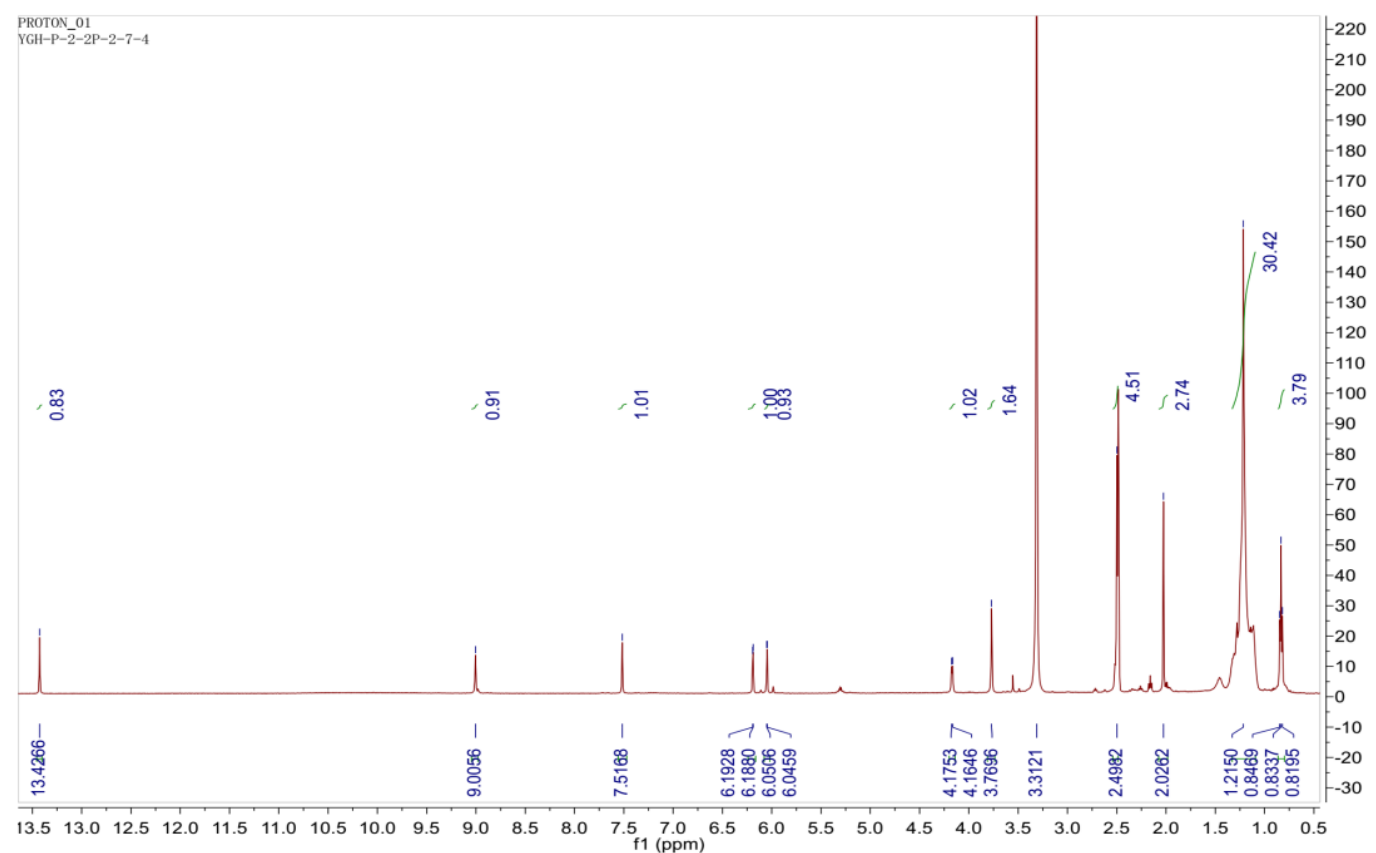

Figure S8. ${ }^{13} \mathrm{C}$ NMR spectrum $(125 \mathrm{MHz})$ of penixylarin A (1) in DMSO- $d_{6}$

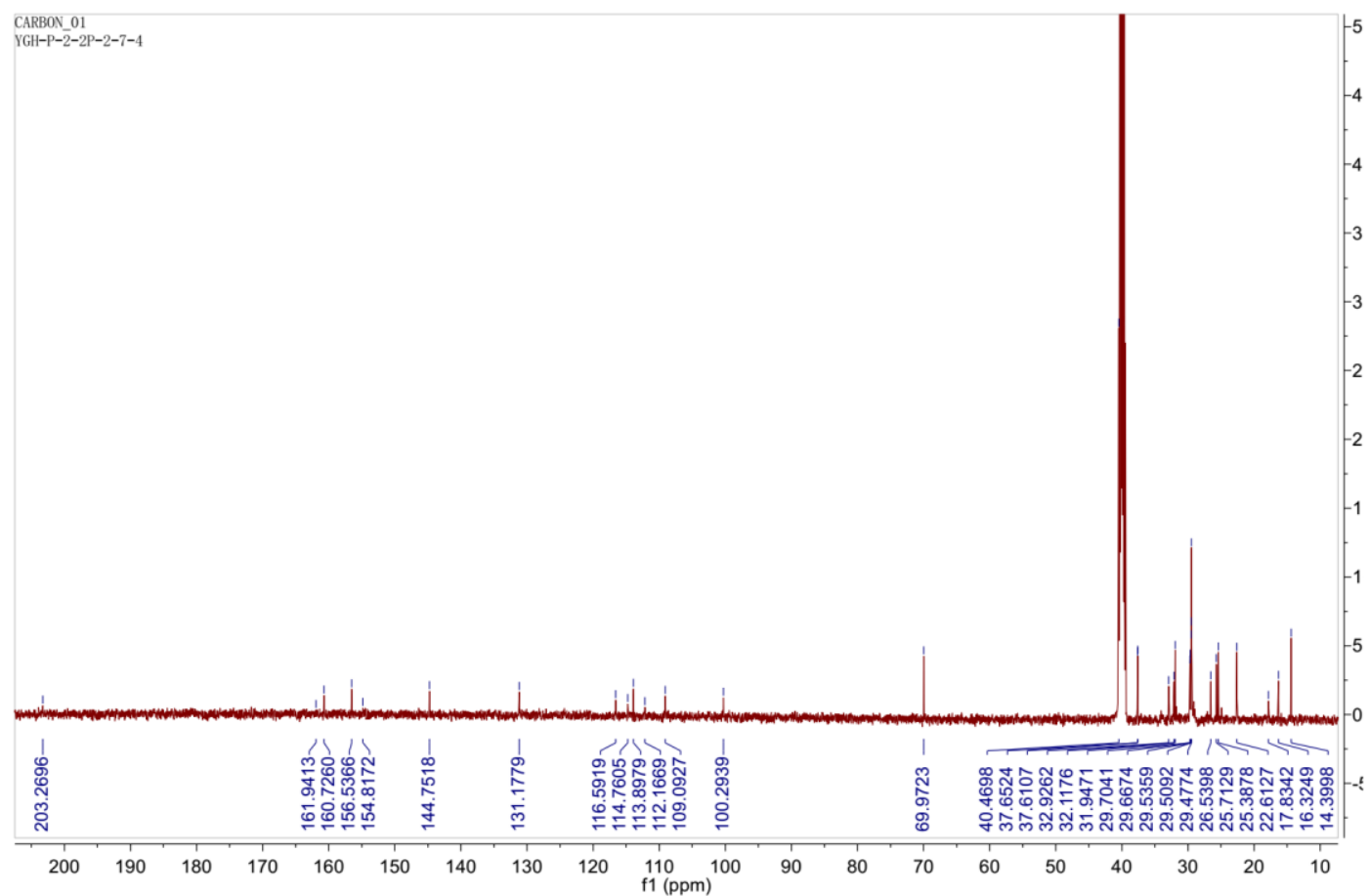


Figure S9. HSQC spectrum of penixylarin A (1)

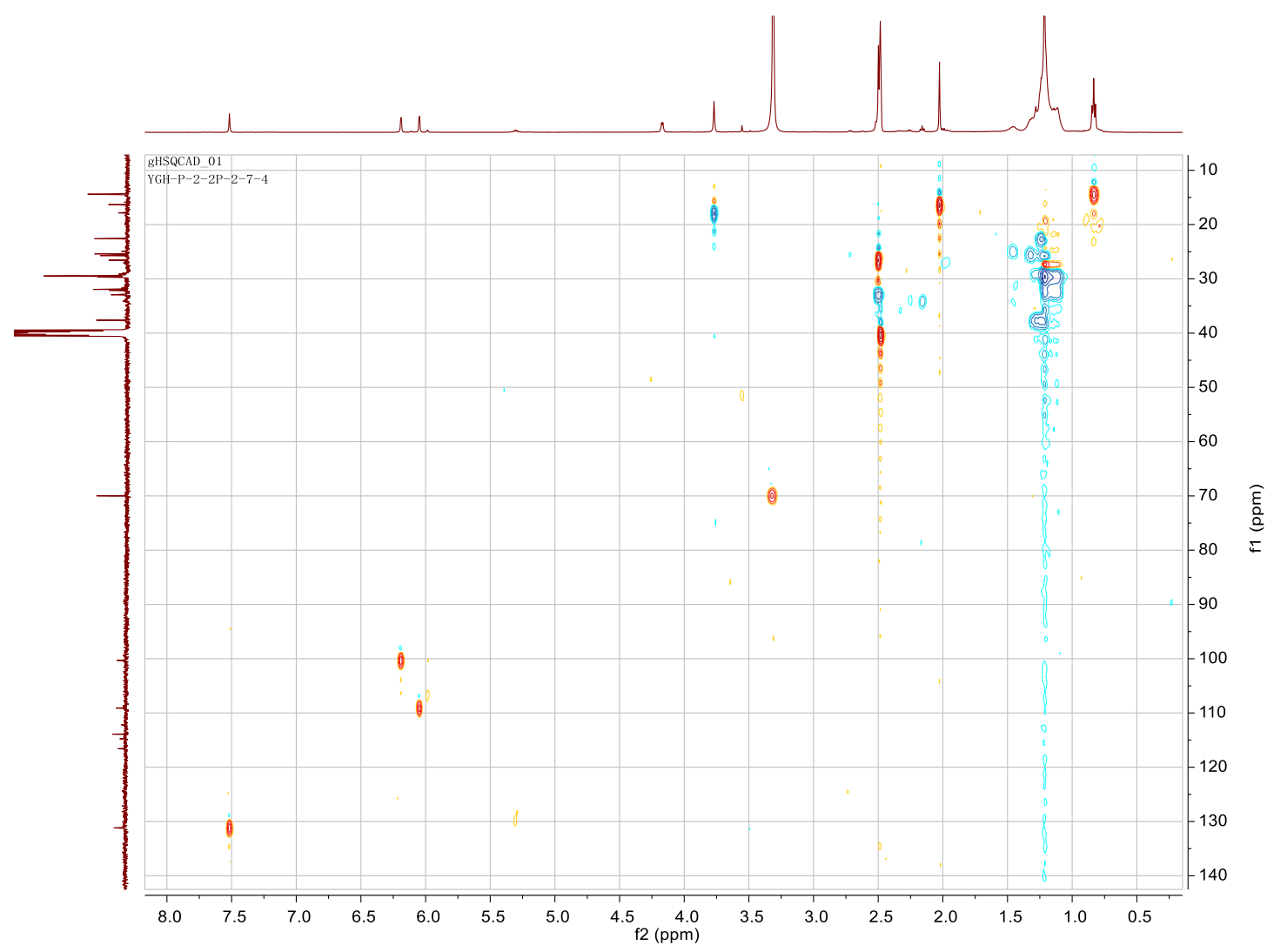

Figure S10. ${ }^{1} \mathrm{H}-{ }^{1} \mathrm{H}$ COSY spectrum of penixylarin $\mathrm{A}(\mathbf{1})$

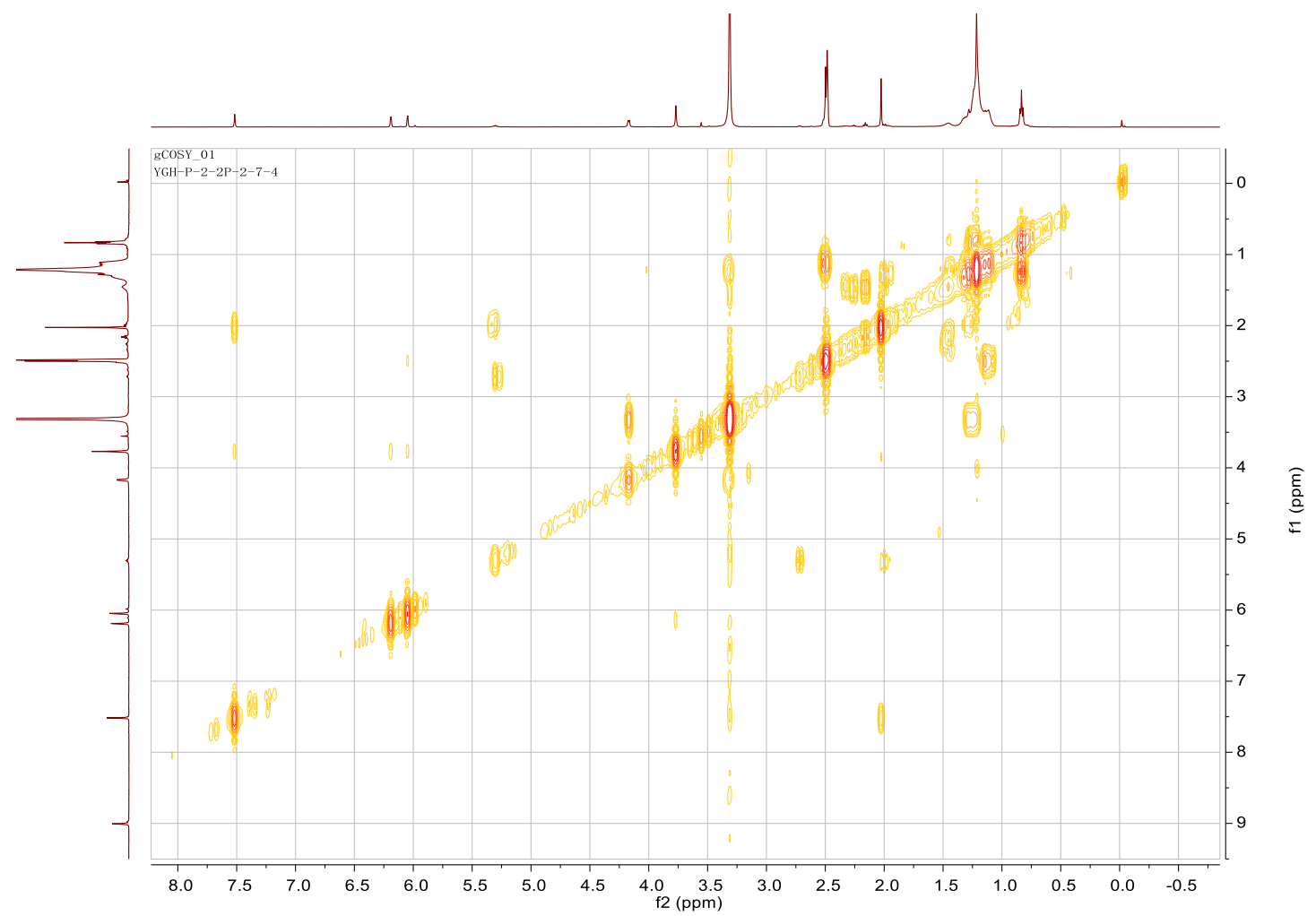


Figure S11. HMBC spectrum of penixylarin A (1)

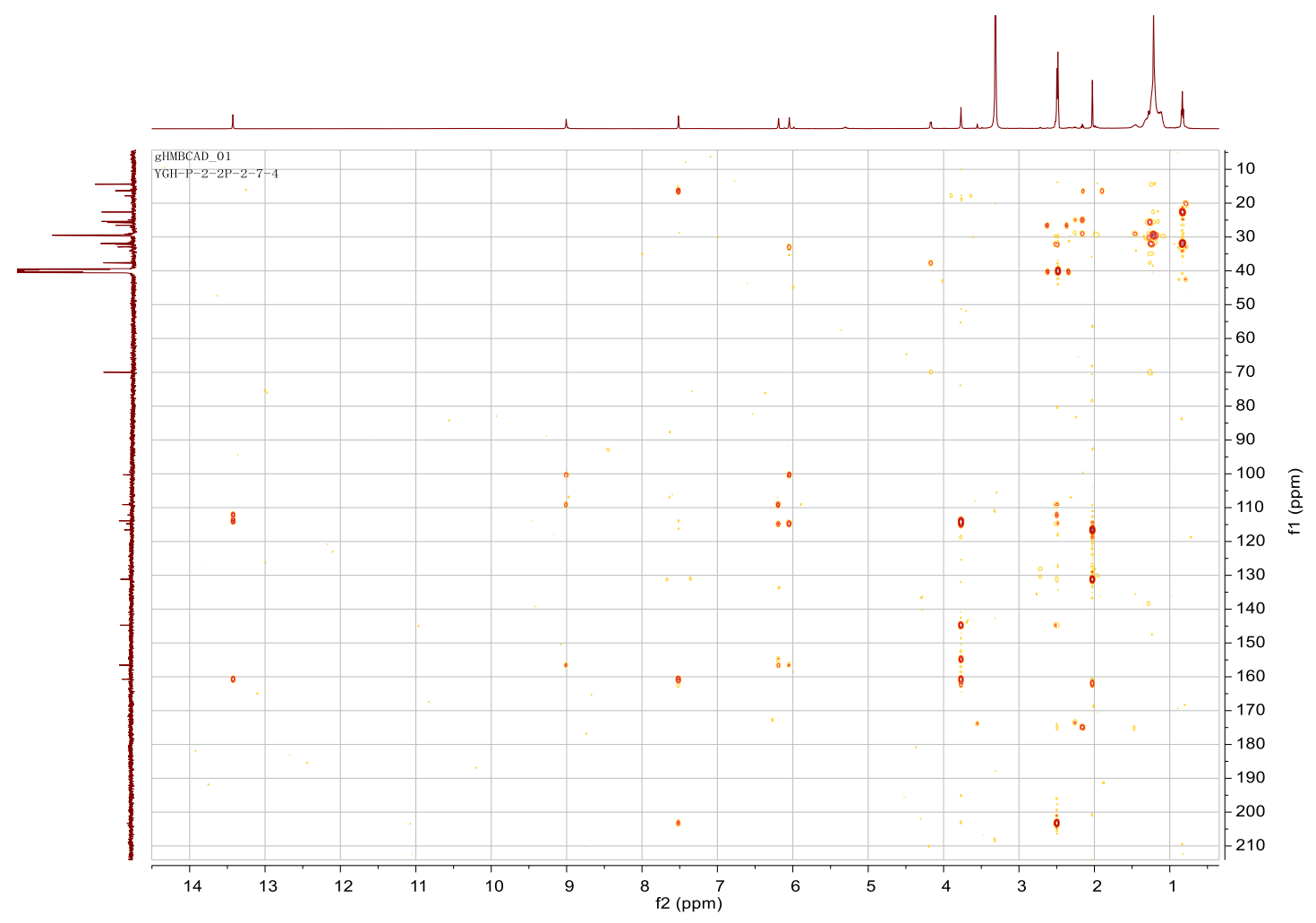

Figure S12. HRESIMS spectrum of penixylarin A (1)

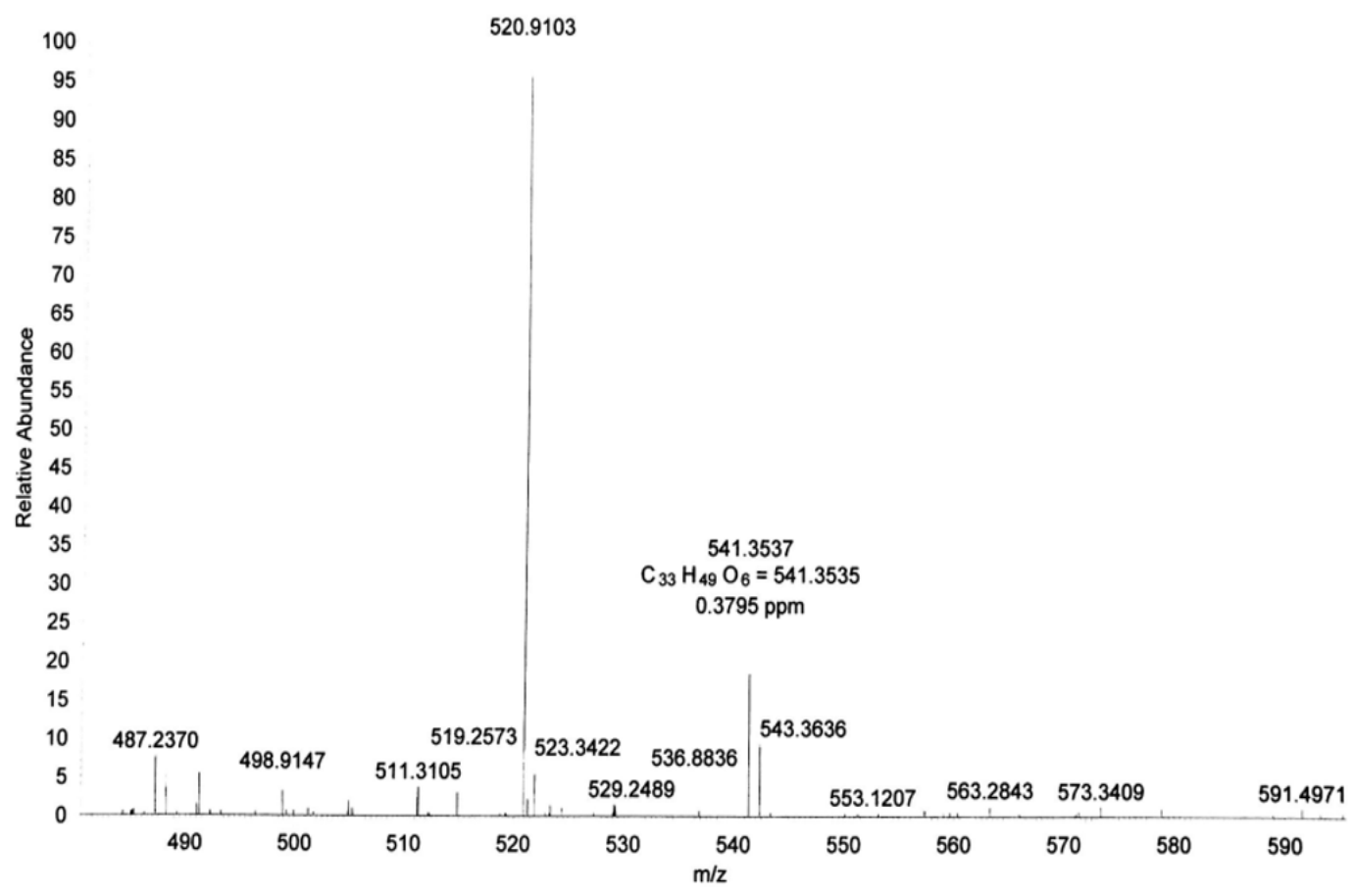


Figure S13. ${ }^{1} \mathrm{H}$ NMR spectrum $(500 \mathrm{MHz})$ of penixylarin B (2) in DMSO- $d_{6}$

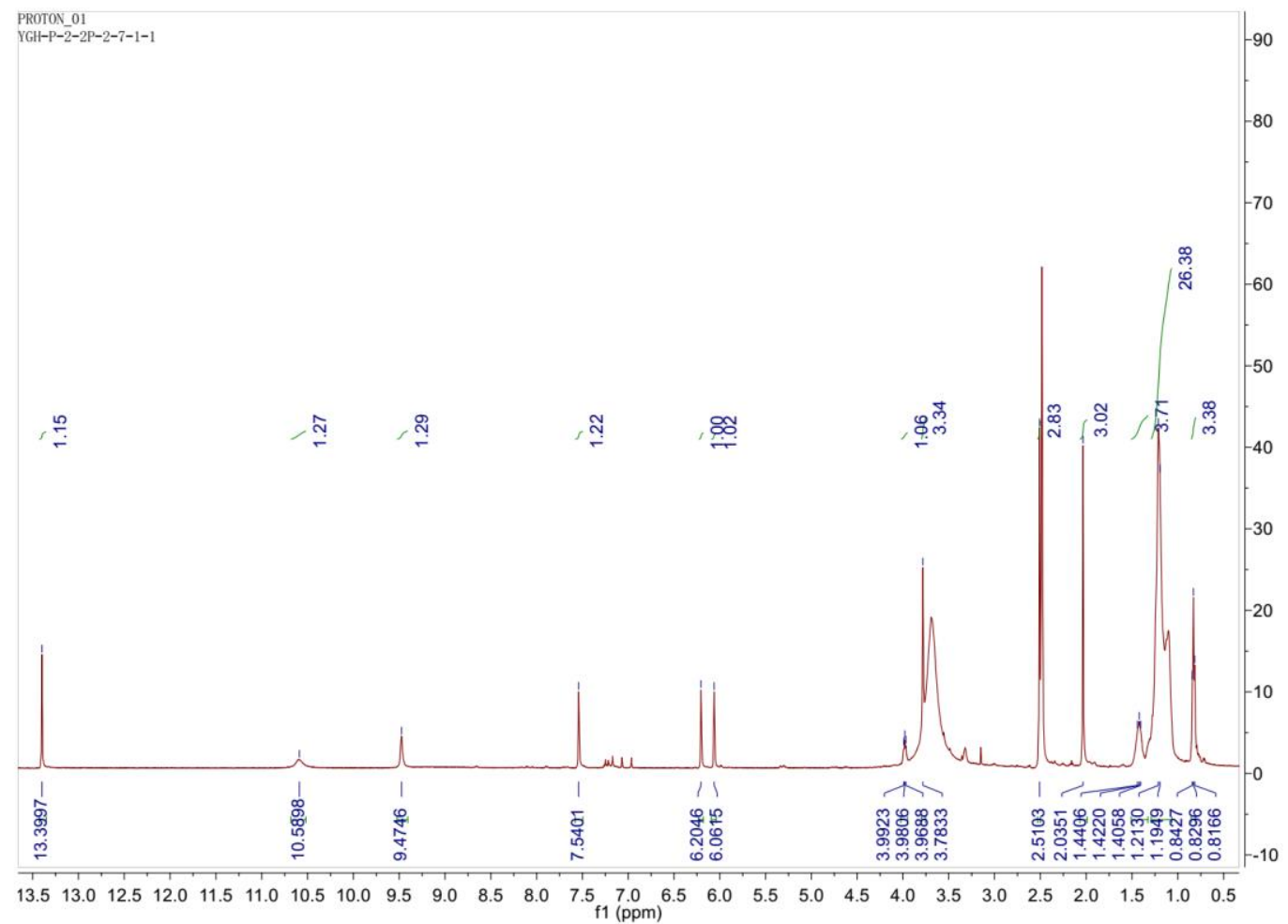

Figure S14. ${ }^{13} \mathrm{C}$ NMR spectrum $(125 \mathrm{MHz})$ of penixylarin B (2) in DMSO- $d_{6}$

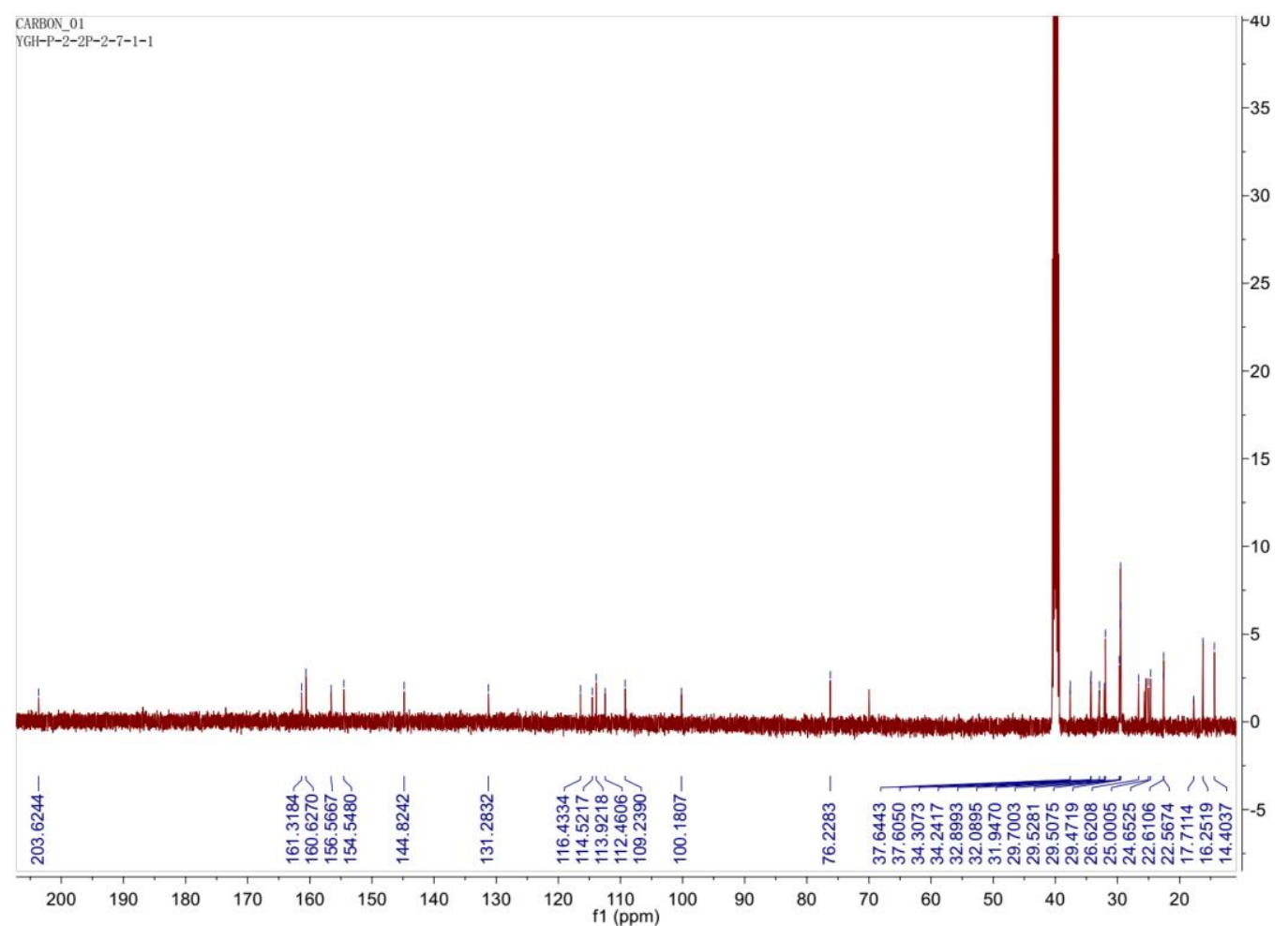


Figure S15. HSQC spectrum of penixylarin B (2)

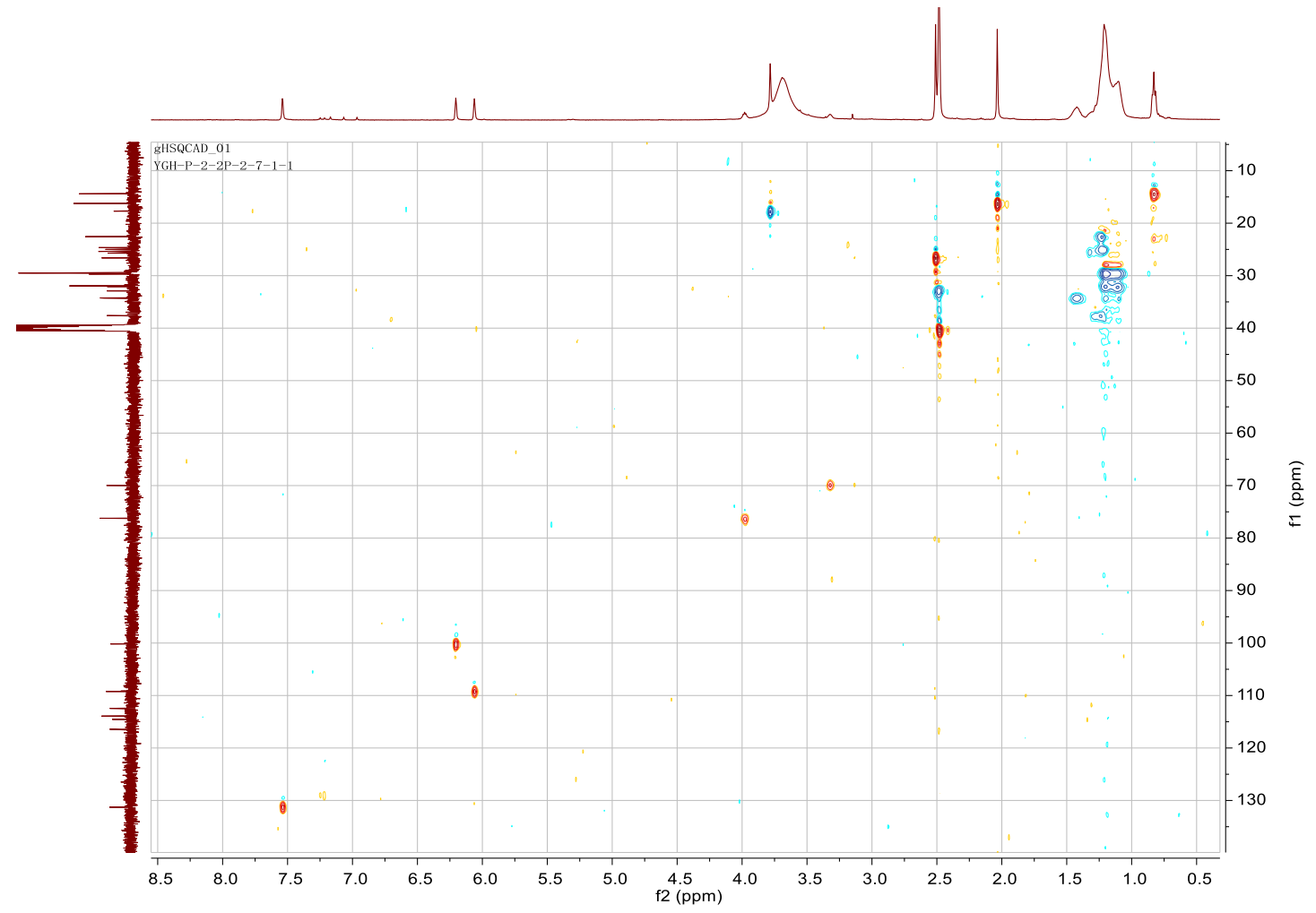

Figure S16. ${ }^{1} \mathrm{H}-{ }^{1} \mathrm{H}$ COSY spectrum of penixylarin B (2)

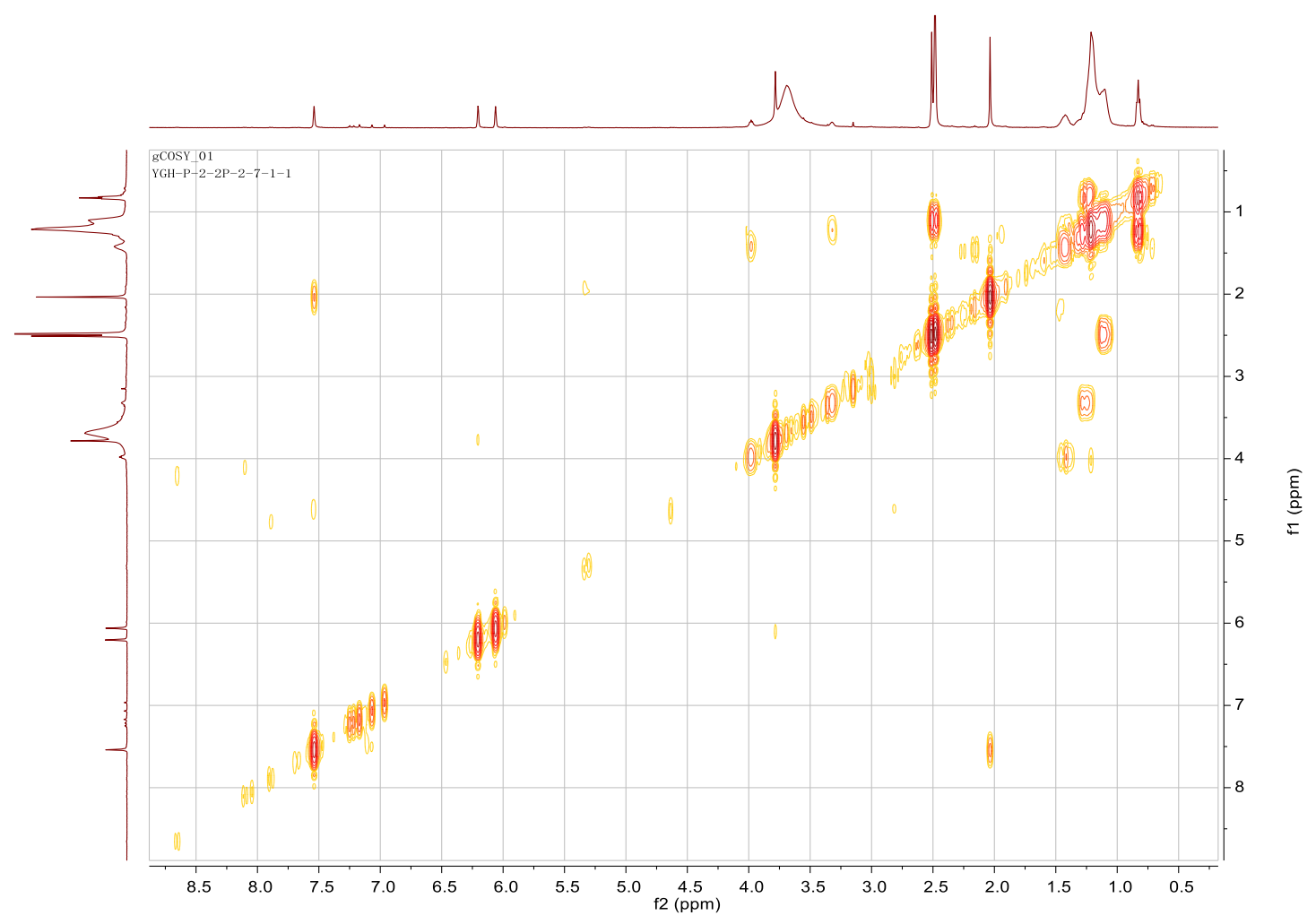


Figure S17. HMBC spectrum of penixylarin B (2)

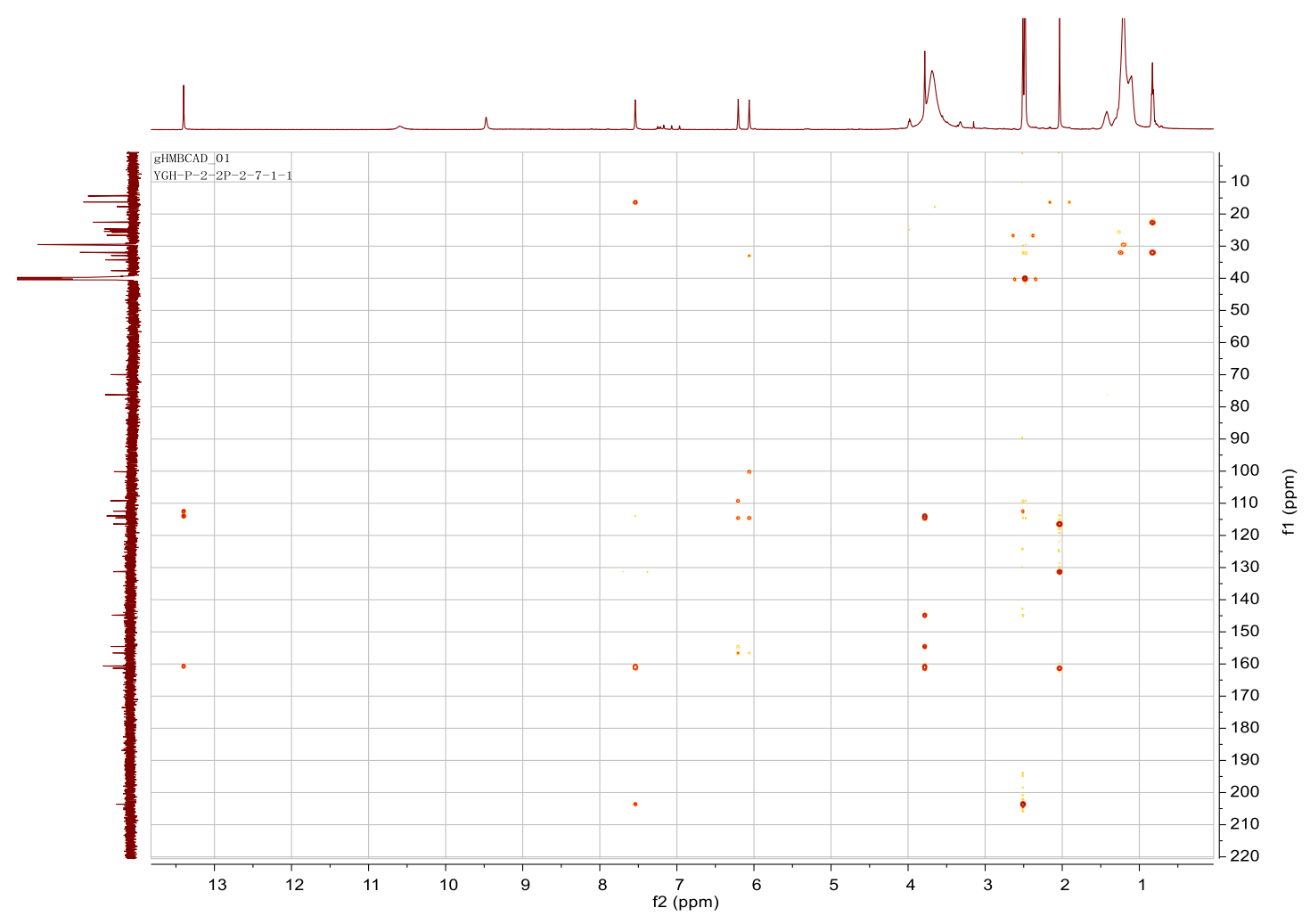

Figure S18. HRESIMS spectrum of penixylarin B (2)

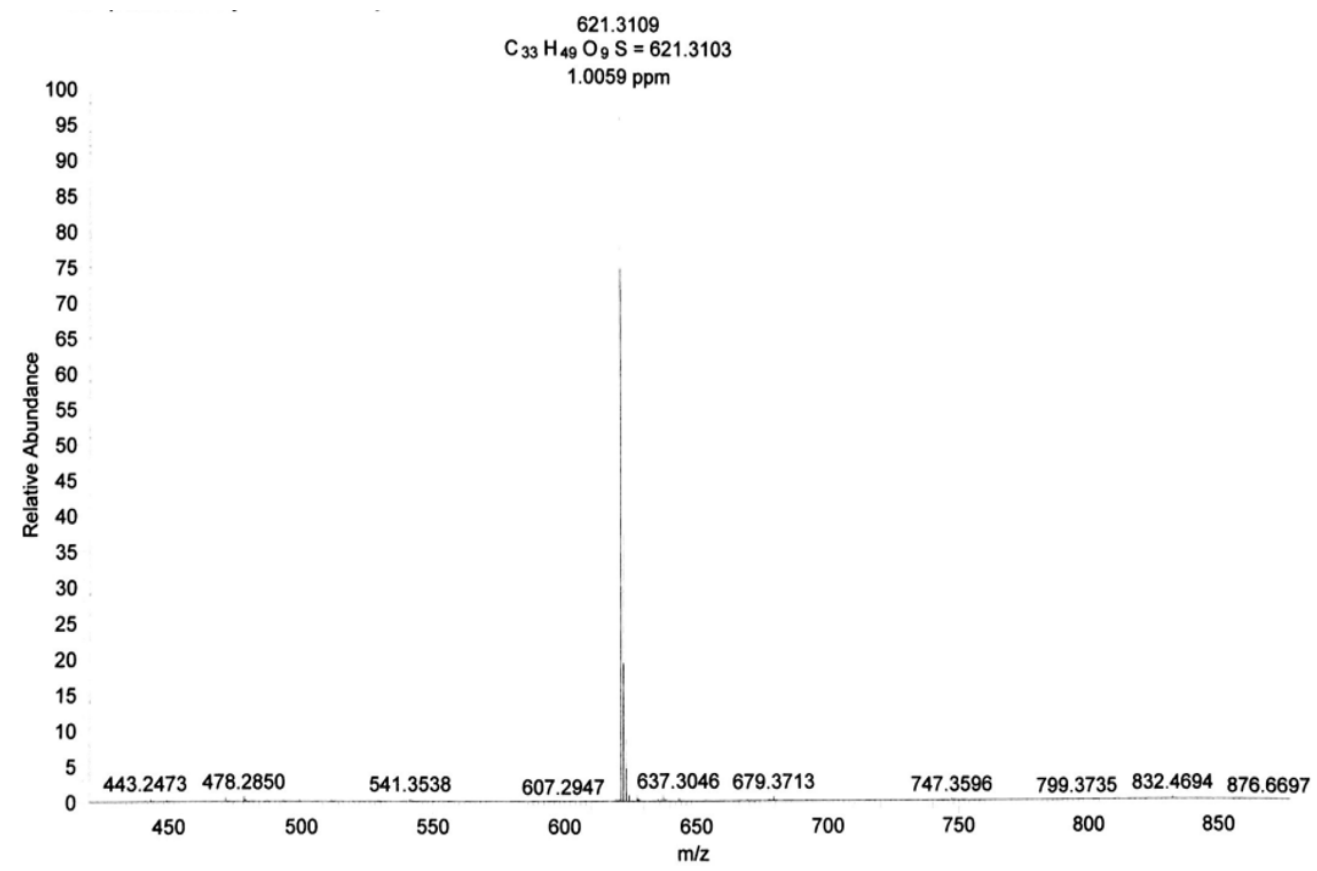


Figure S19. ${ }^{1} \mathrm{H}$ NMR spectrum $(500 \mathrm{MHz})$ of penixylarin C (3) in DMSO- $d_{6}$

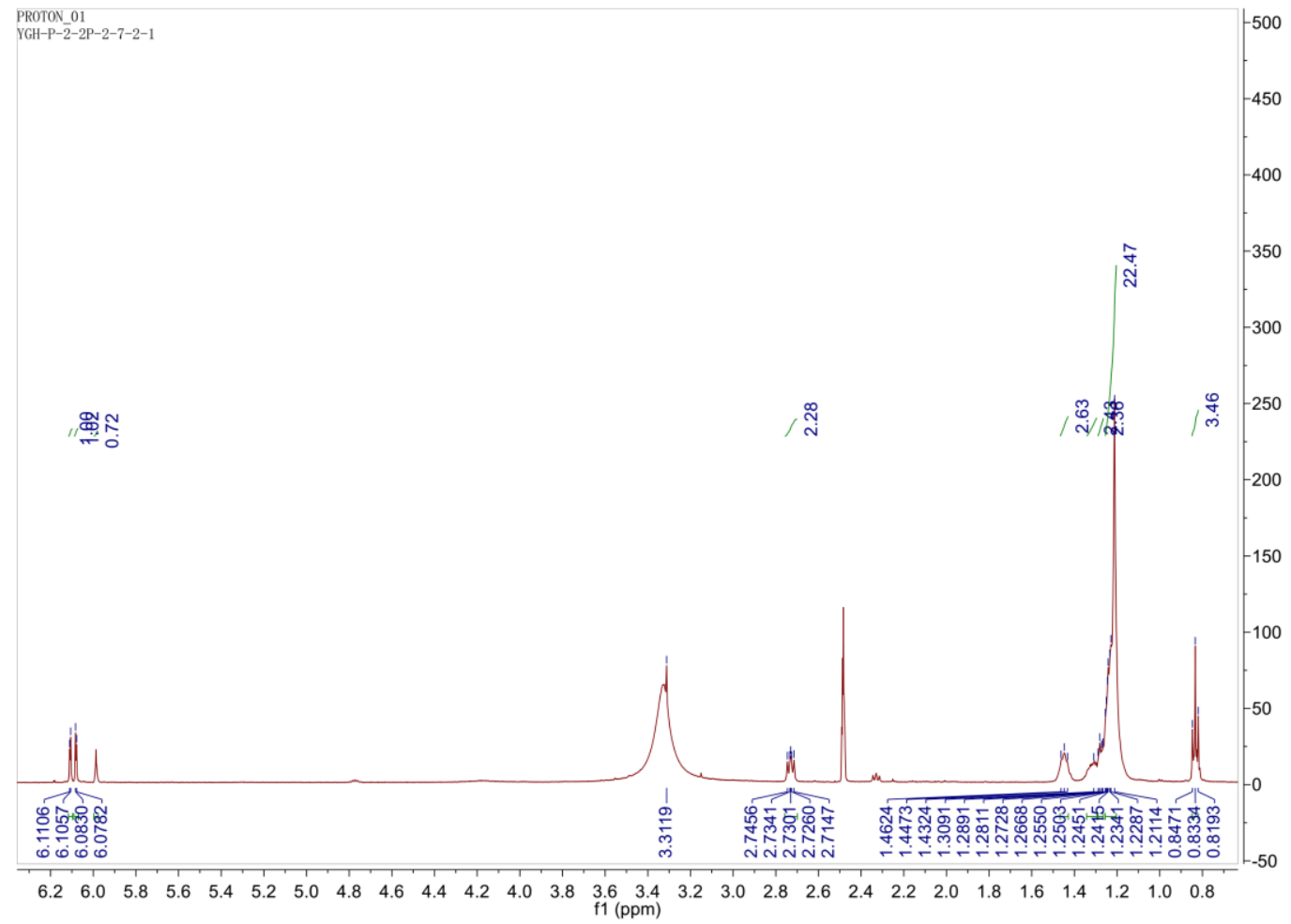

Figure S20. ${ }^{13} \mathrm{C}$ NMR spectrum $(125 \mathrm{MHz})$ of penixylarin C (3) in DMSO- $d_{6}$

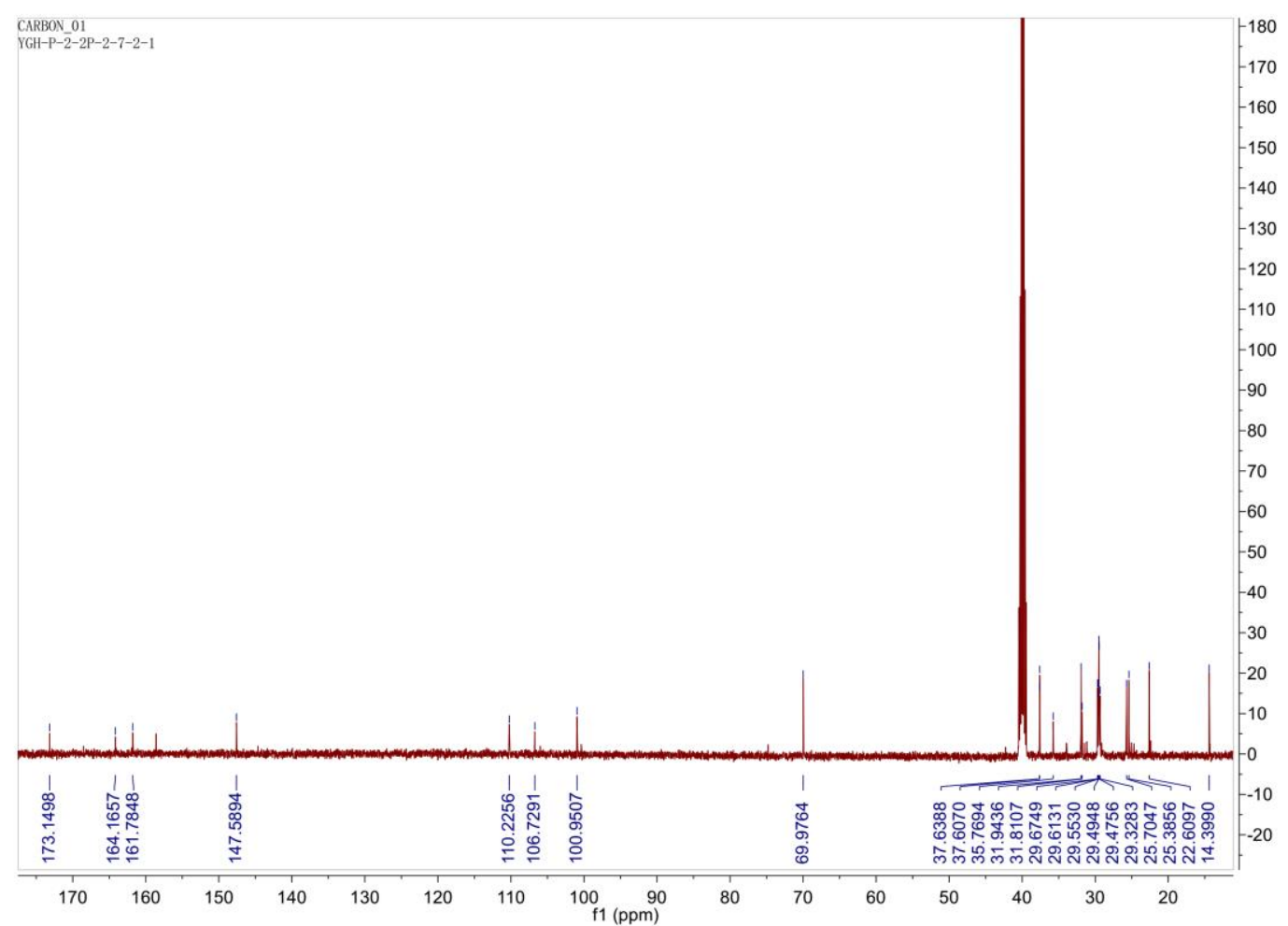


Figure S21. HSQC spectrum of penixylarin C (3)

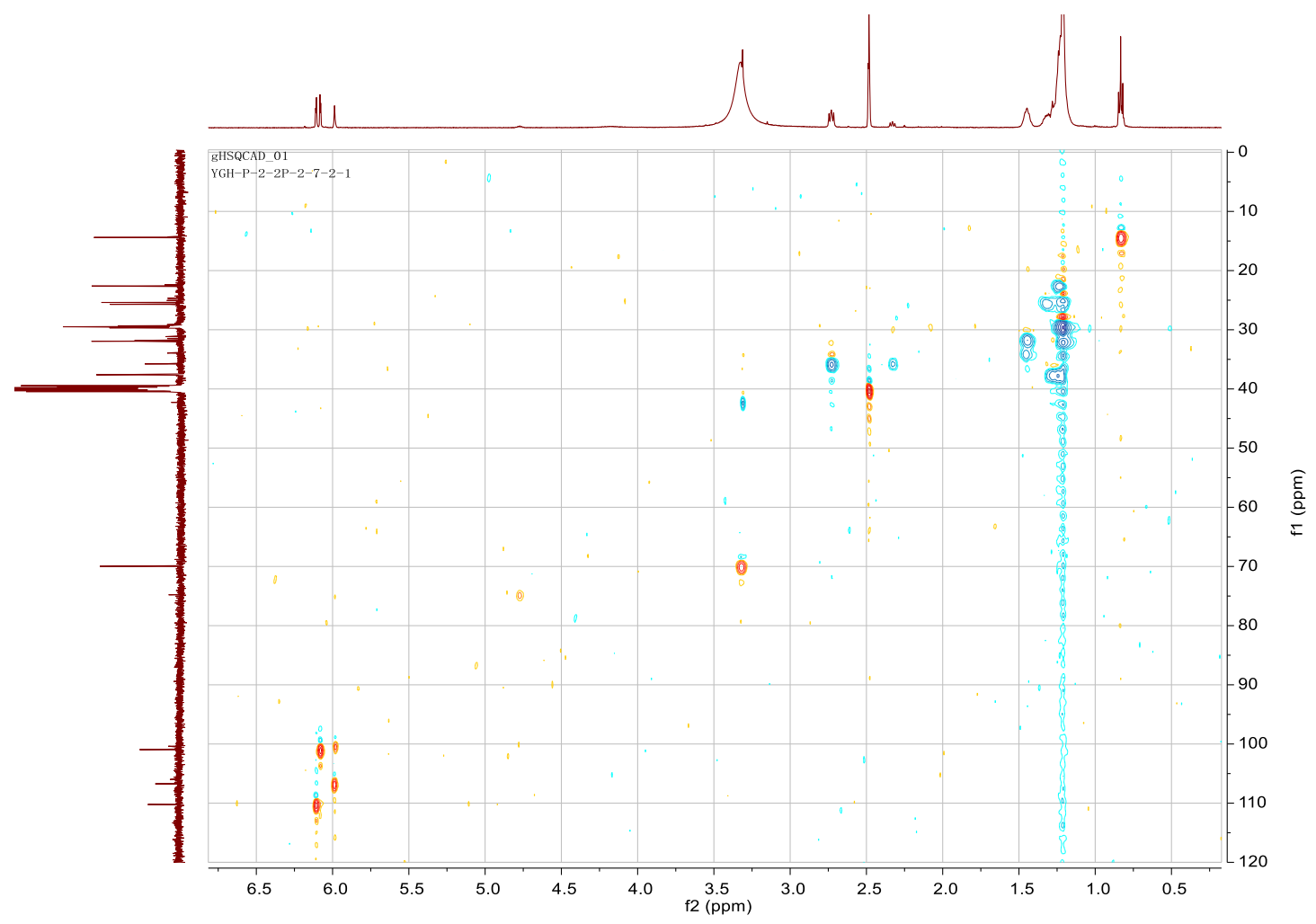

Figure S22. ${ }^{1} \mathrm{H}-{ }^{1} \mathrm{H}$ COSY spectrum of penixylarin $\mathrm{C} \mathrm{(3)}$

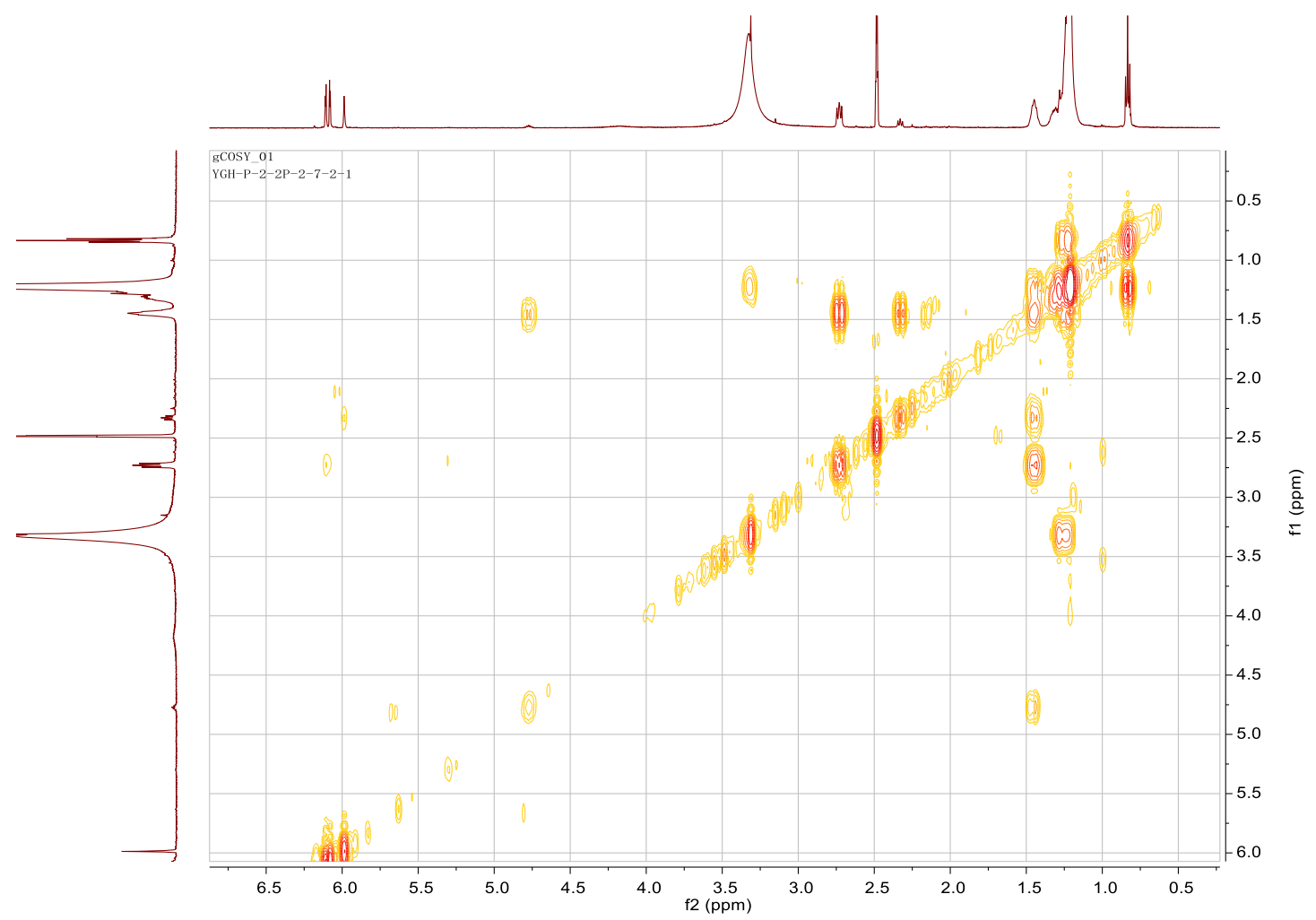


Figure S23. HMBC spectrum of penixylarin C (3)

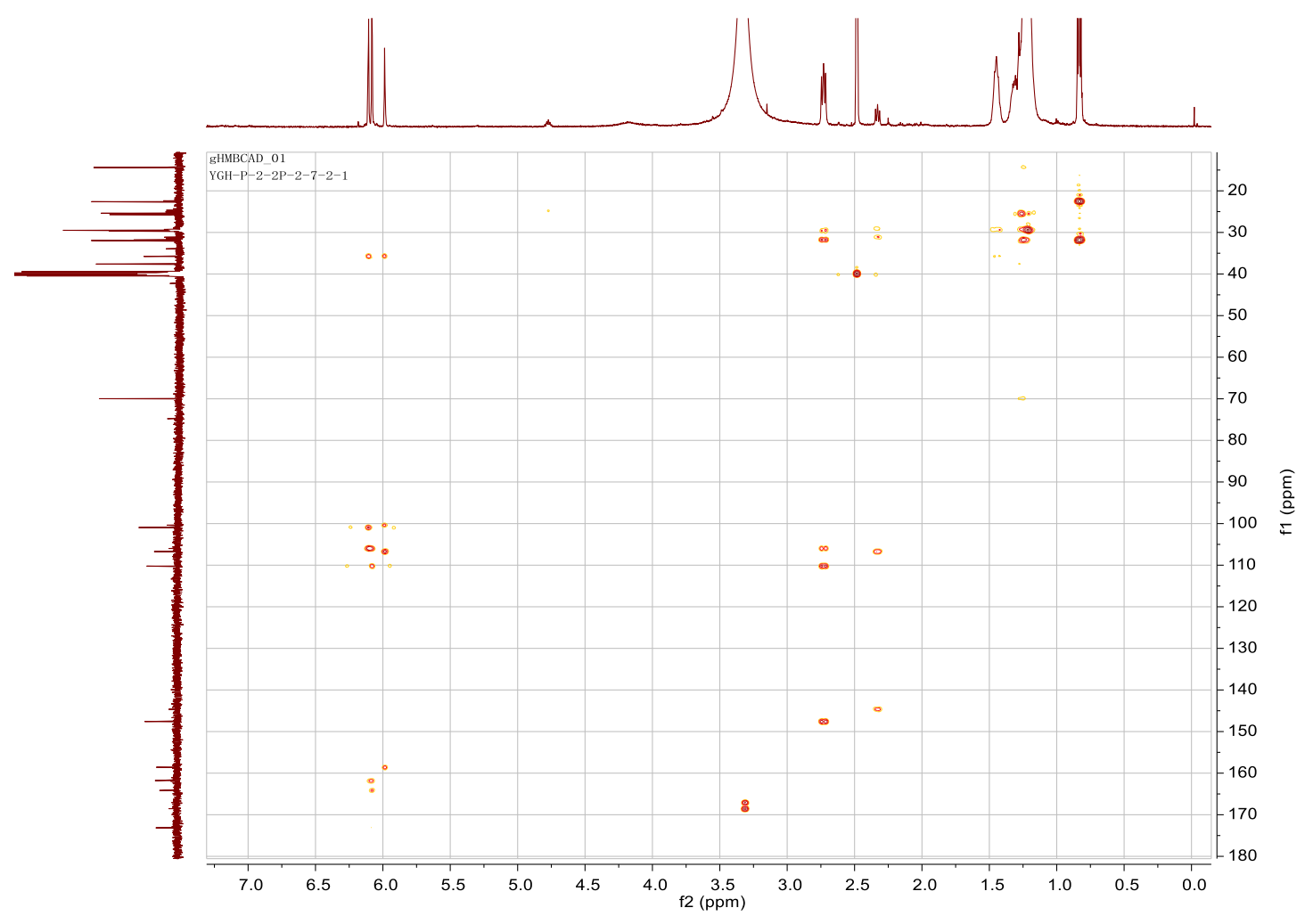

Figure S24. HRESIMS spectrum of penixylarin C (3)

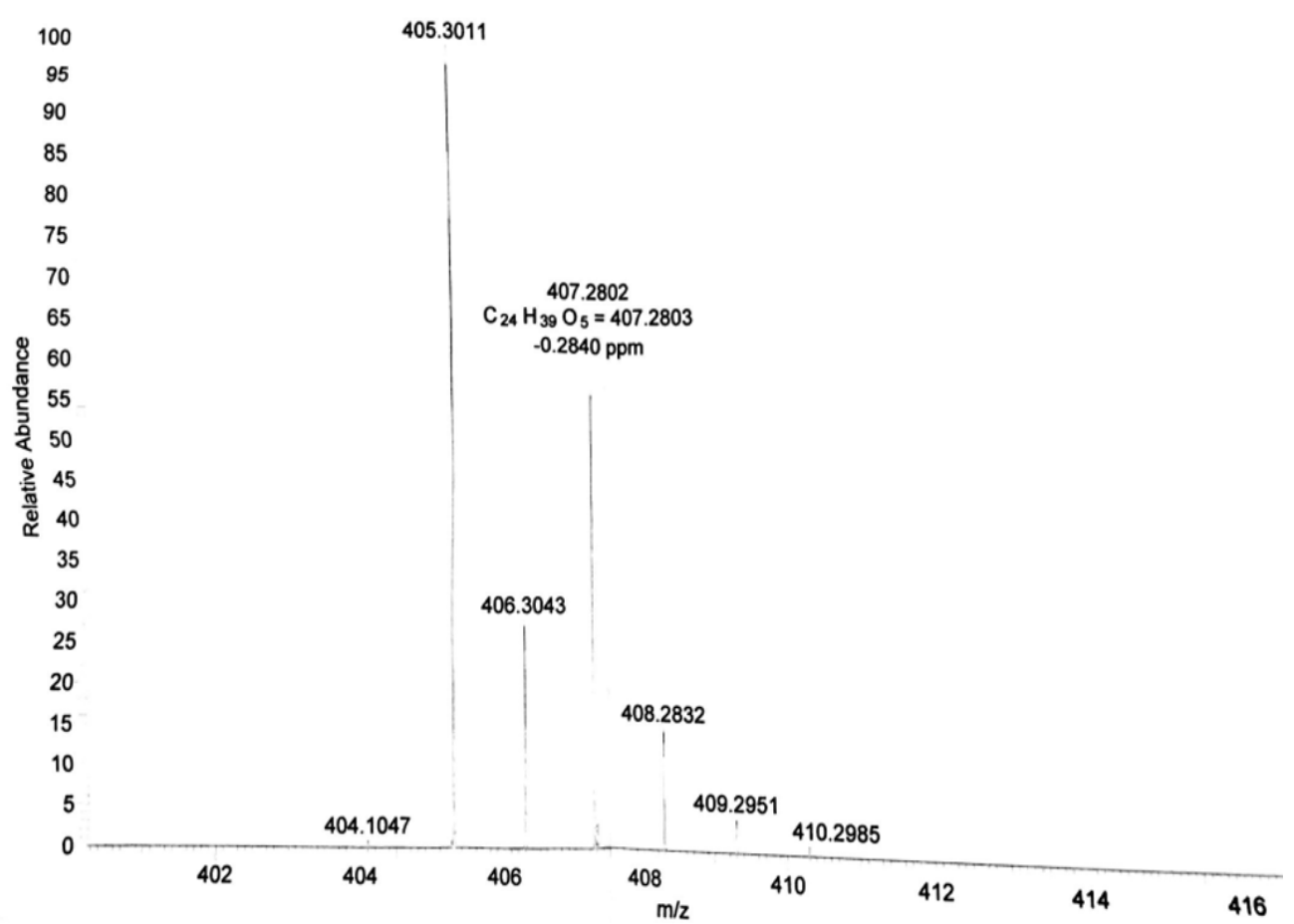


Figure S25. ${ }^{1} \mathrm{H}$ NMR spectrum $(500 \mathrm{MHz})$ of penixylarin D (4) in DMSO- $d_{6}$

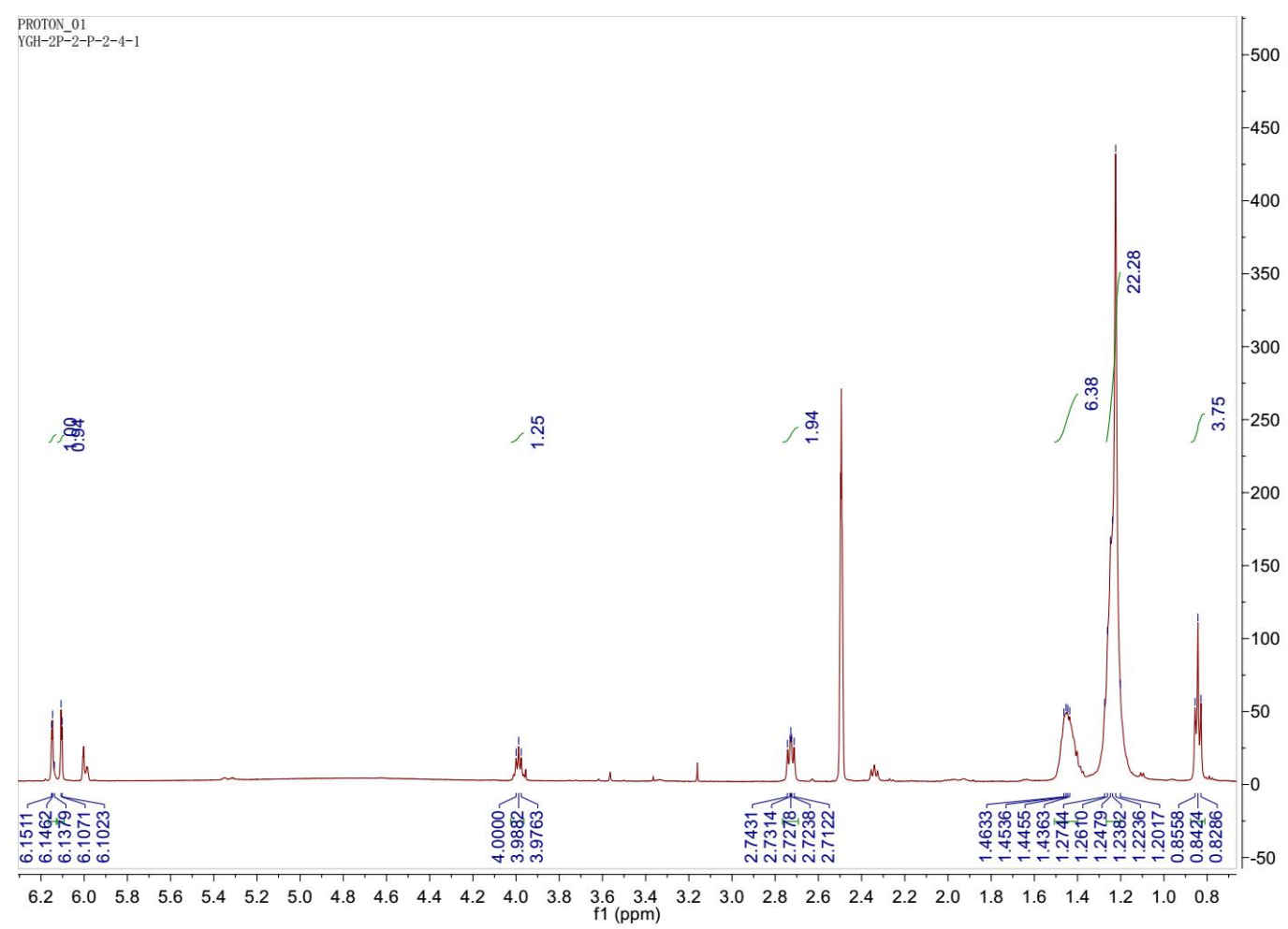

Figure S26. ${ }^{13} \mathrm{C}$ NMR spectrum (125 MHz) of penixylarin D (4) in DMSO- $d_{6}$

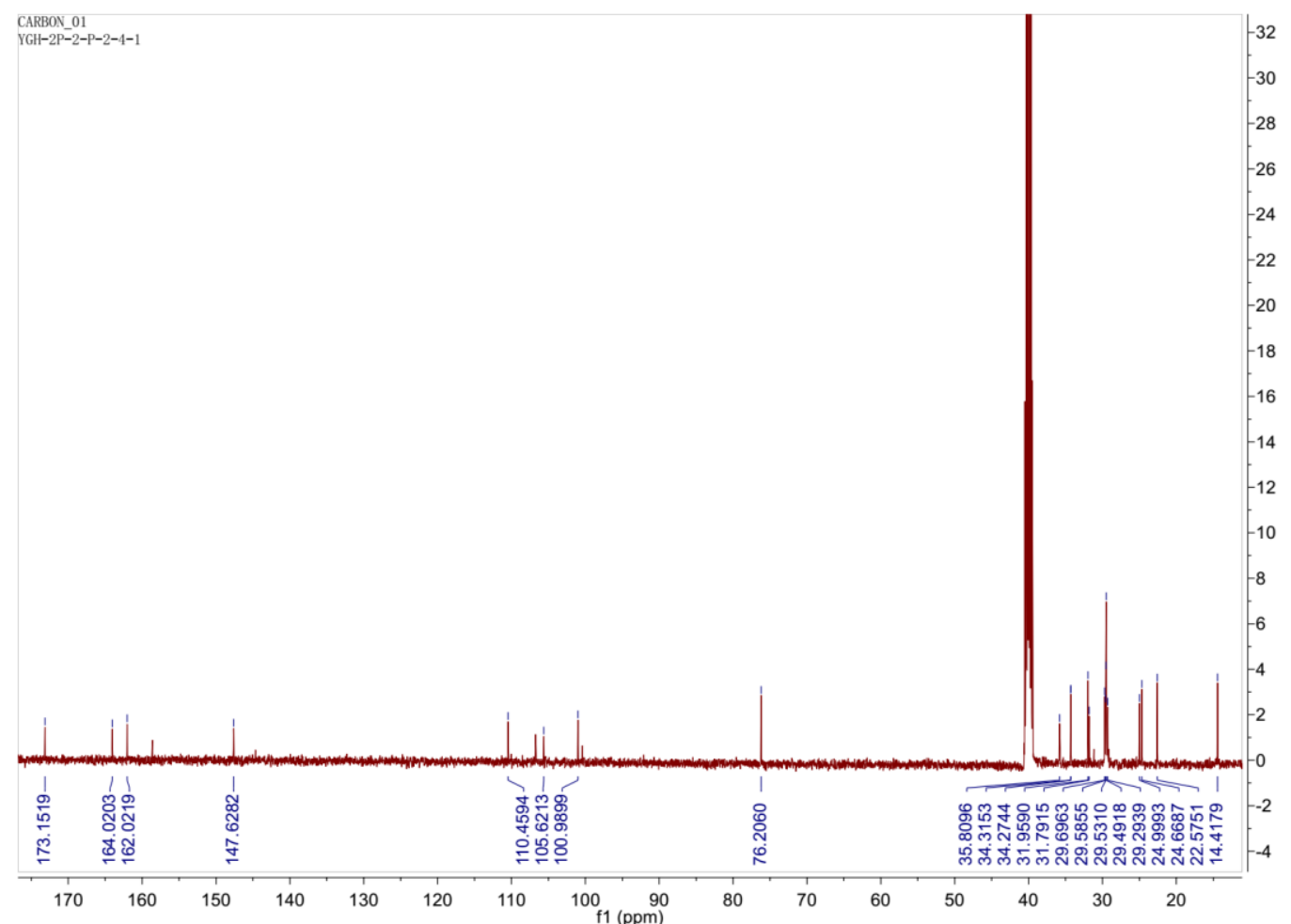


Figure S27. HSQC spectrum of penixylarin D (4)

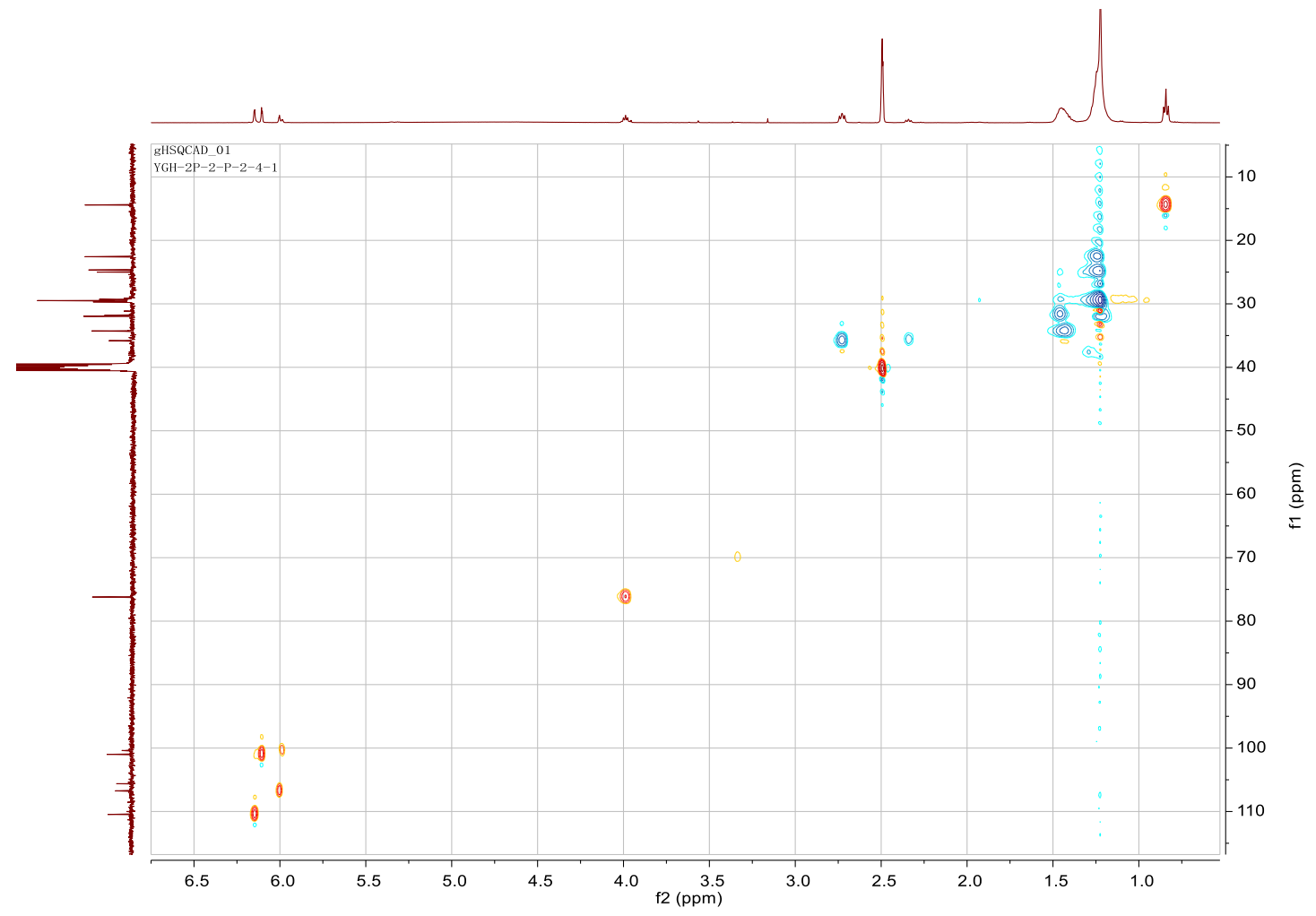

Figure S28. ${ }^{1} \mathrm{H}-{ }^{1} \mathrm{H}$ COSY spectrum of penixylarin D (4)

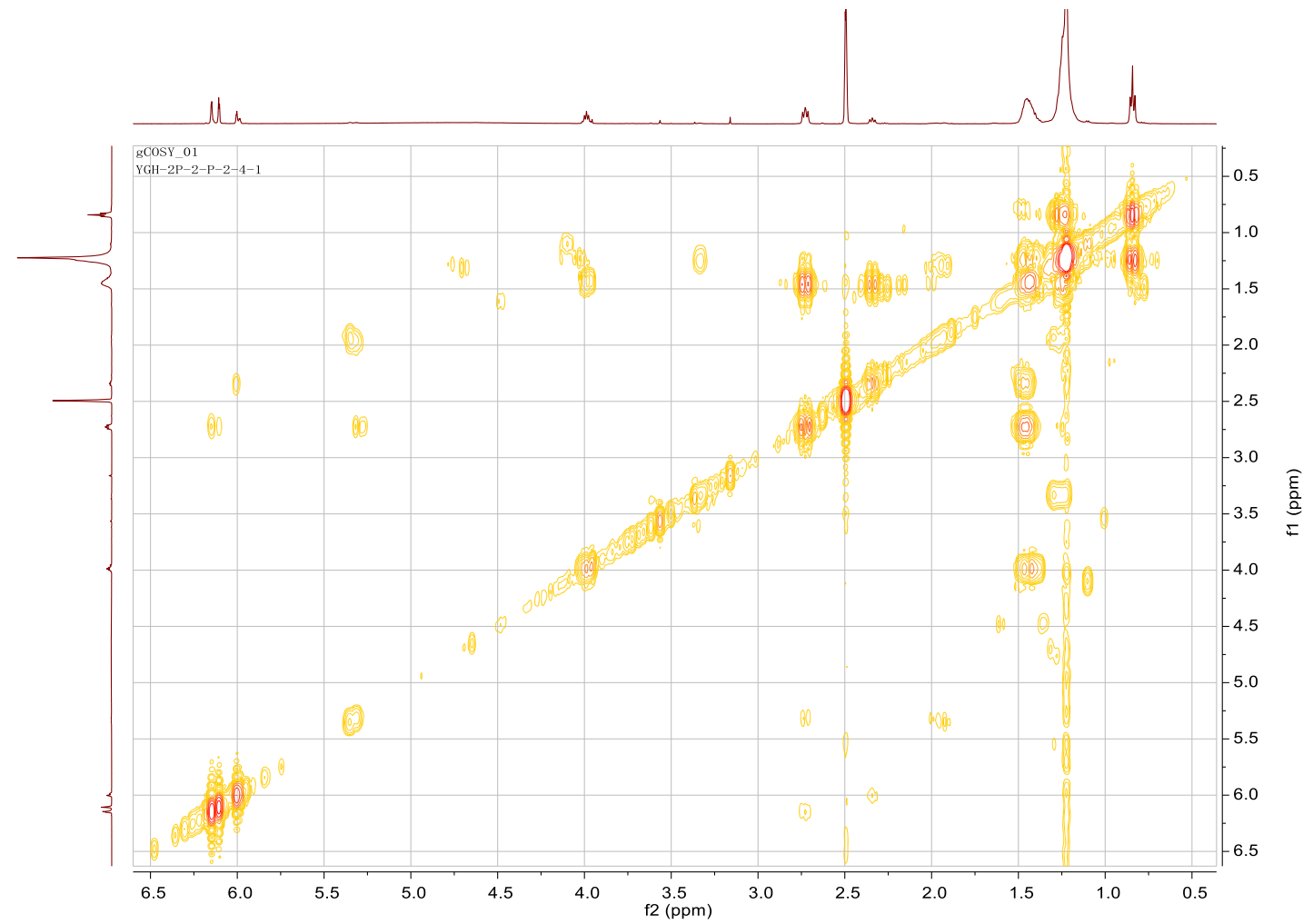


Figure S29. HMBC spectrum of penixylarin D (4)

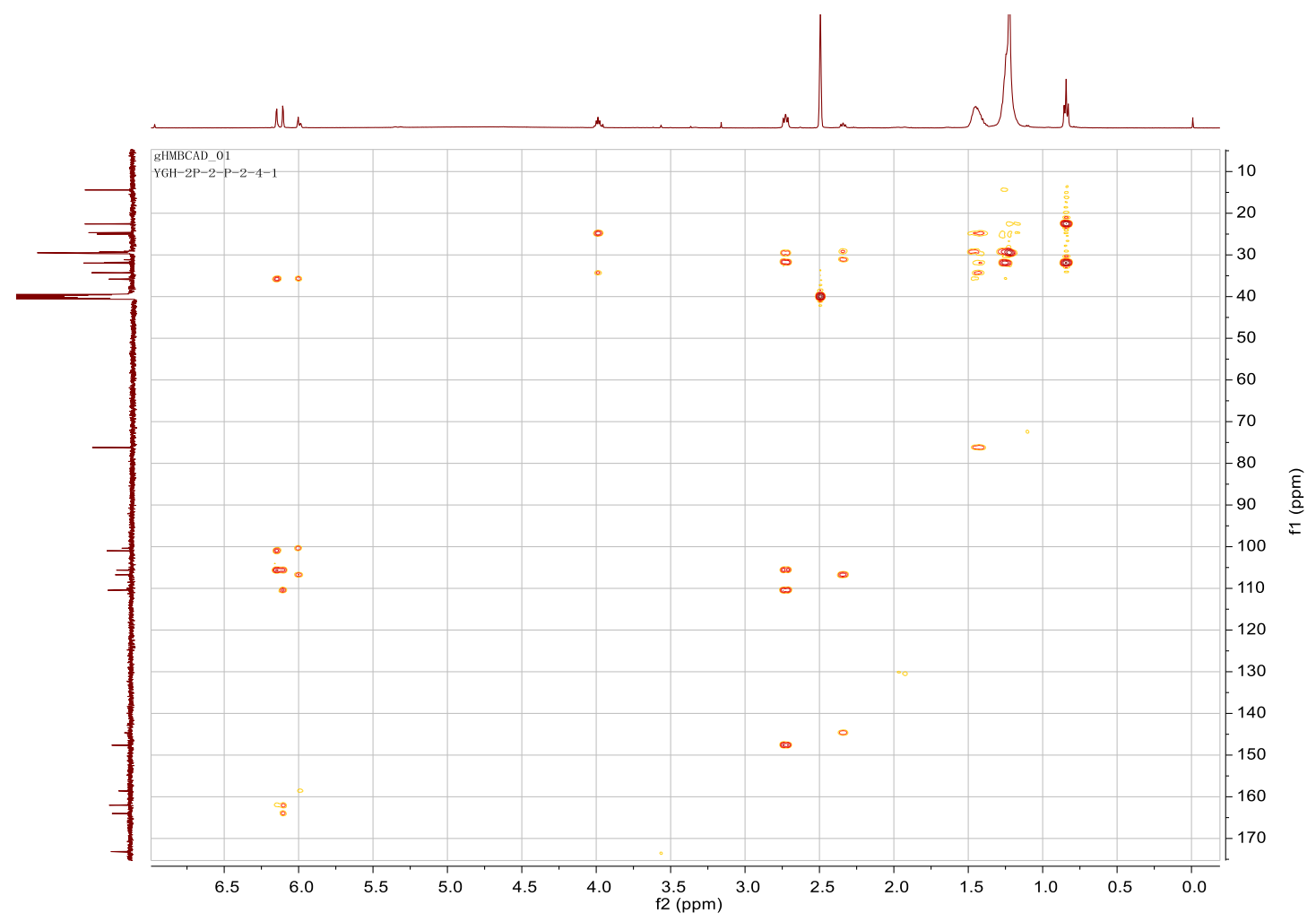

Figure S30. HRESIMS spectrum of penixylarin D (4)

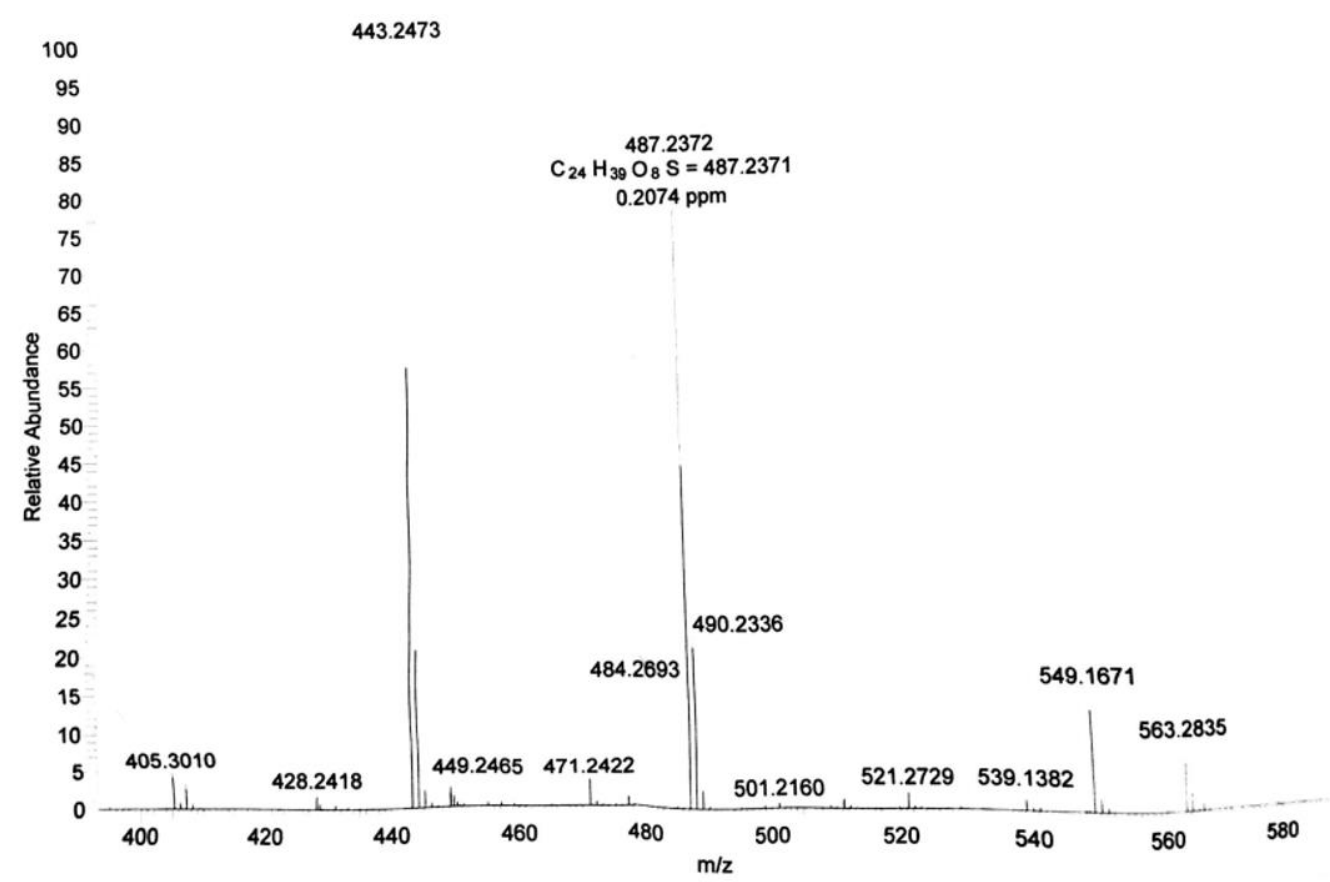


Figure S31. ${ }^{1} \mathrm{H}$ NMR spectrum $(500 \mathrm{MHz})$ of 5 in DMSO- $d_{6}$

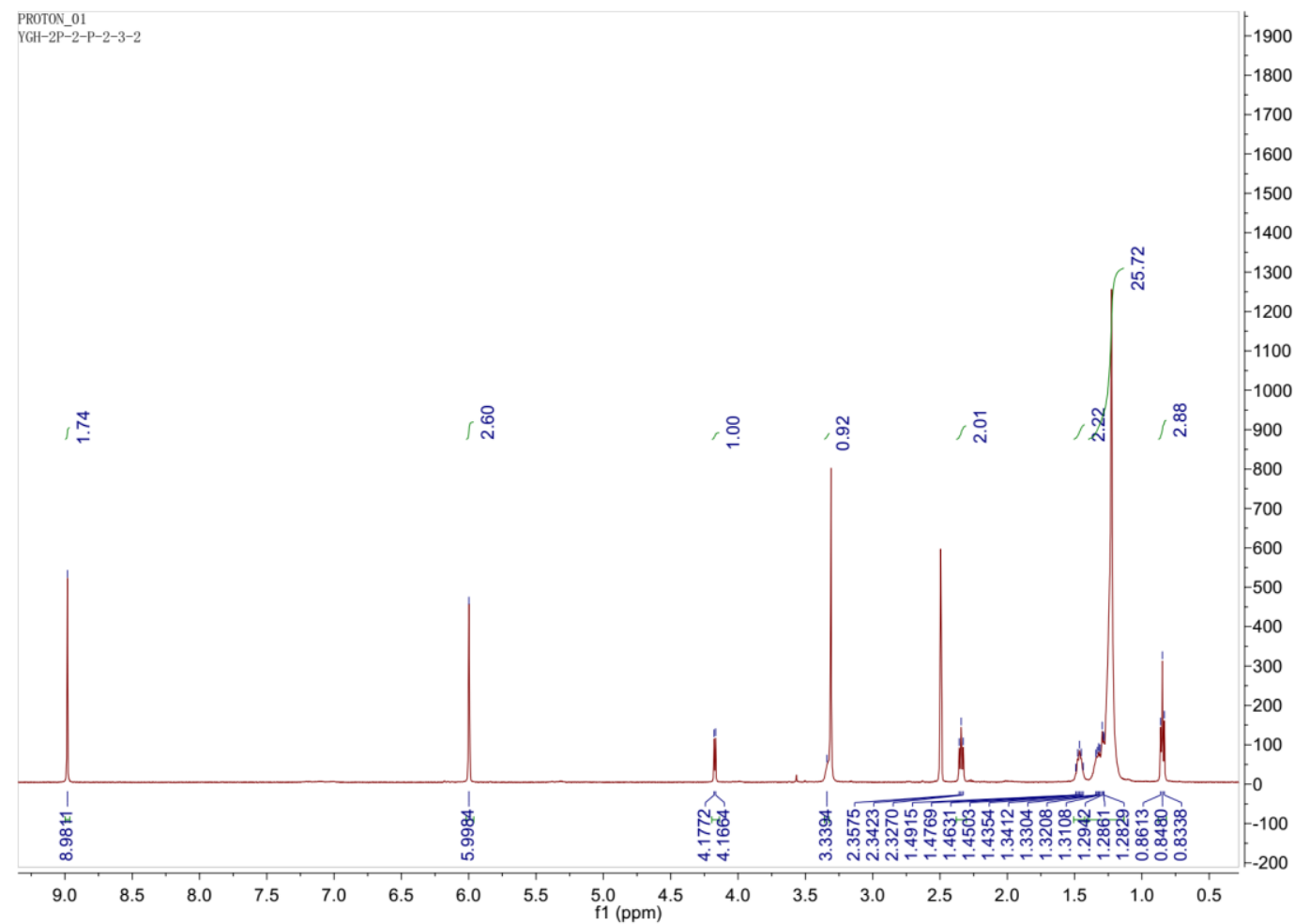

Figure S32. ${ }^{1} \mathrm{H}$ NMR spectrum $(500 \mathrm{MHz})$ of 6 in DMSO- $d_{6}$

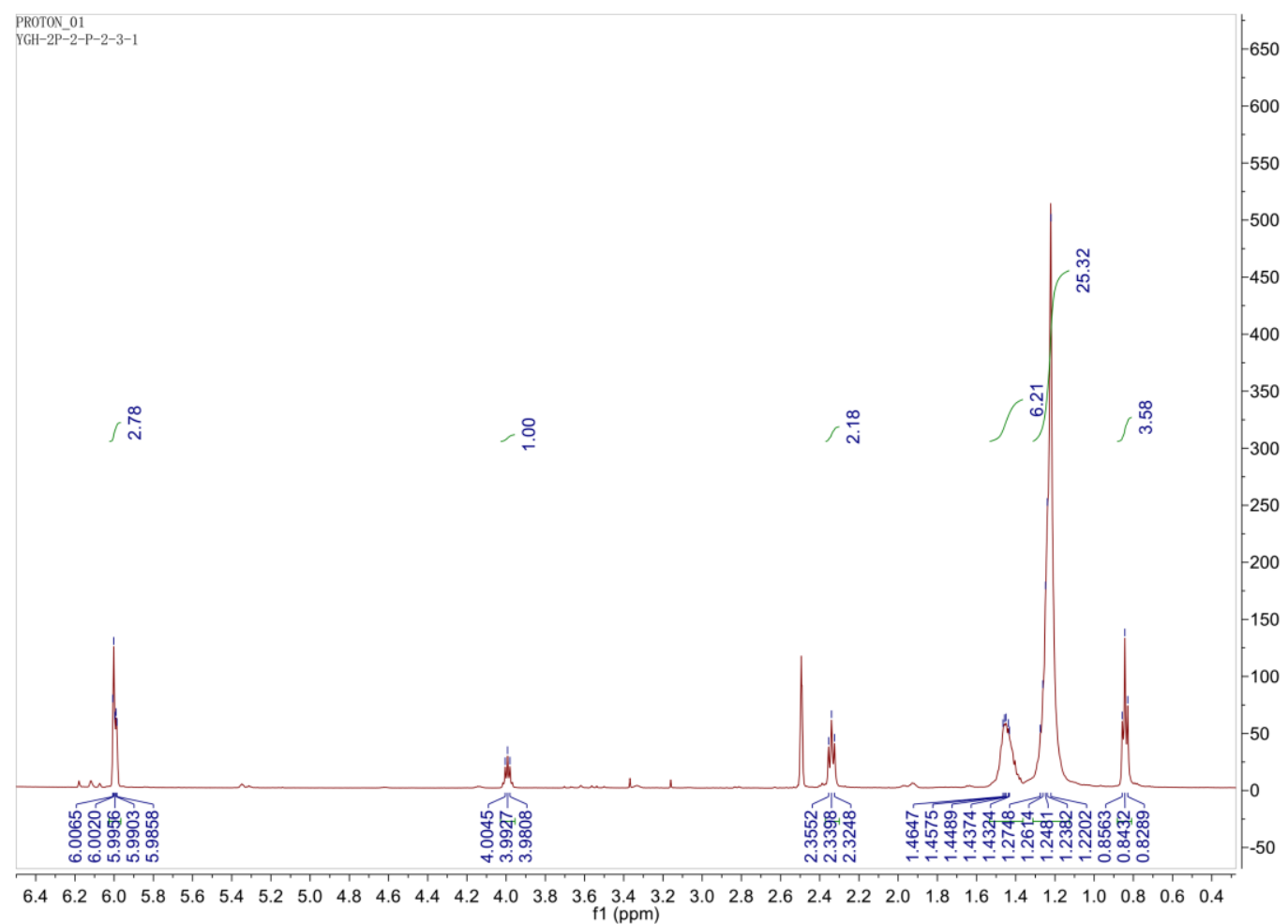


Figure S33. ${ }^{13} \mathrm{C}$ NMR spectrum $(125 \mathrm{MHz})$ of 6 in DMSO- $d_{6}$

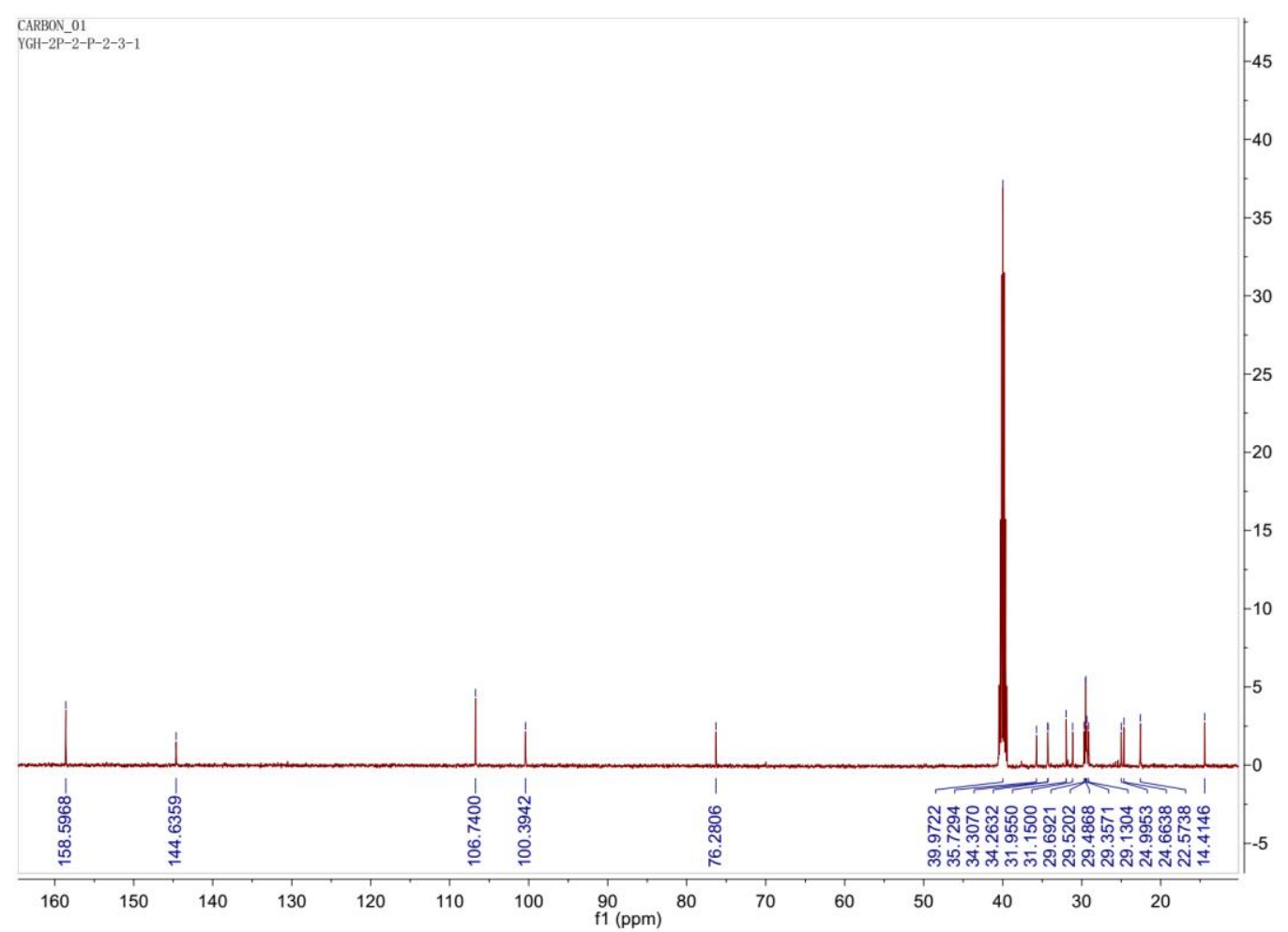

Figure S34. ${ }^{1} \mathrm{H}$ NMR spectrum $(500 \mathrm{MHz})$ of 1a in DMSO- $d_{6}$

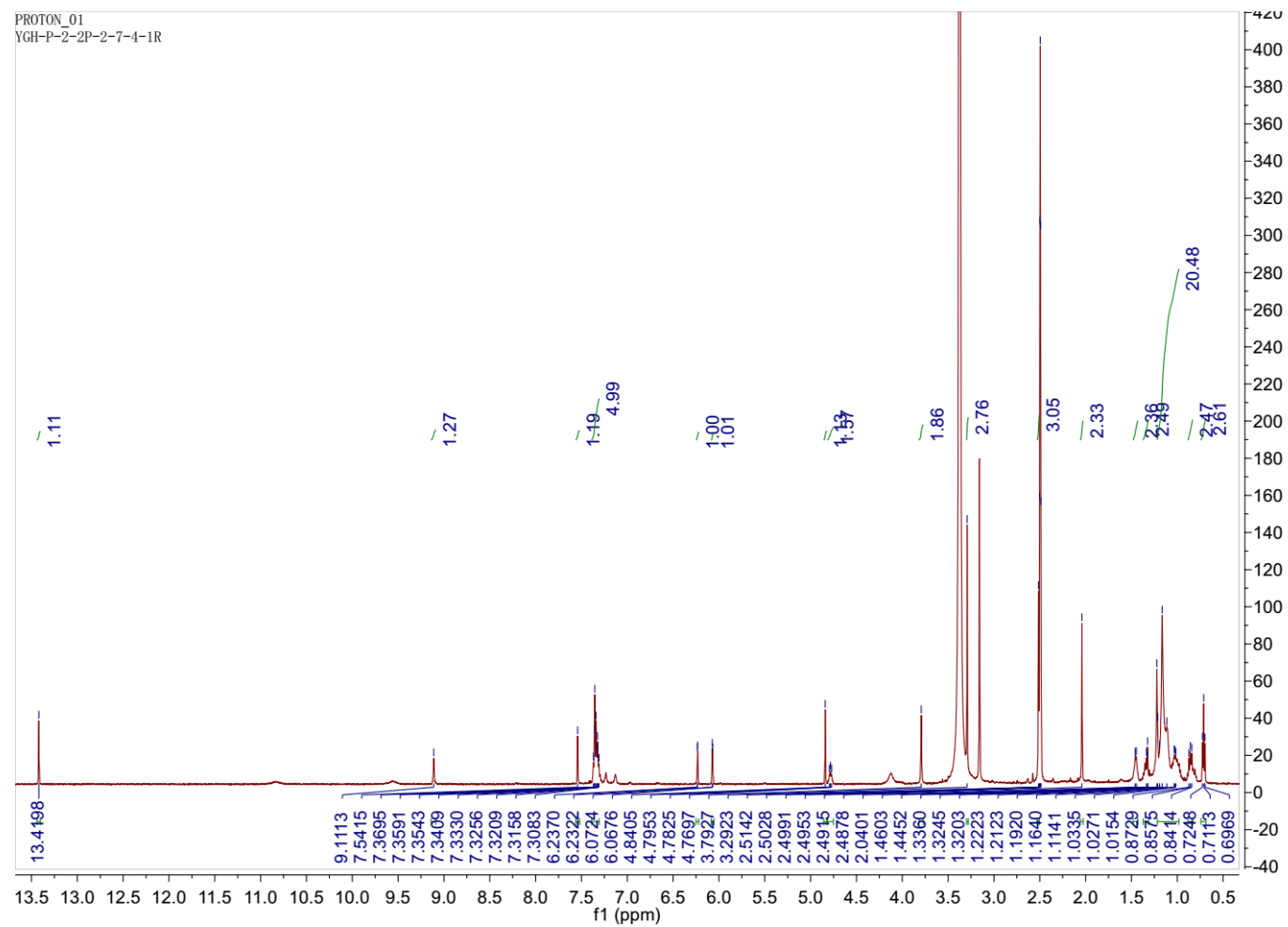


Figure S35. ${ }^{13} \mathrm{C}$ NMR spectrum $(125 \mathrm{MHz})$ of 1a in DMSO- $d_{6}$

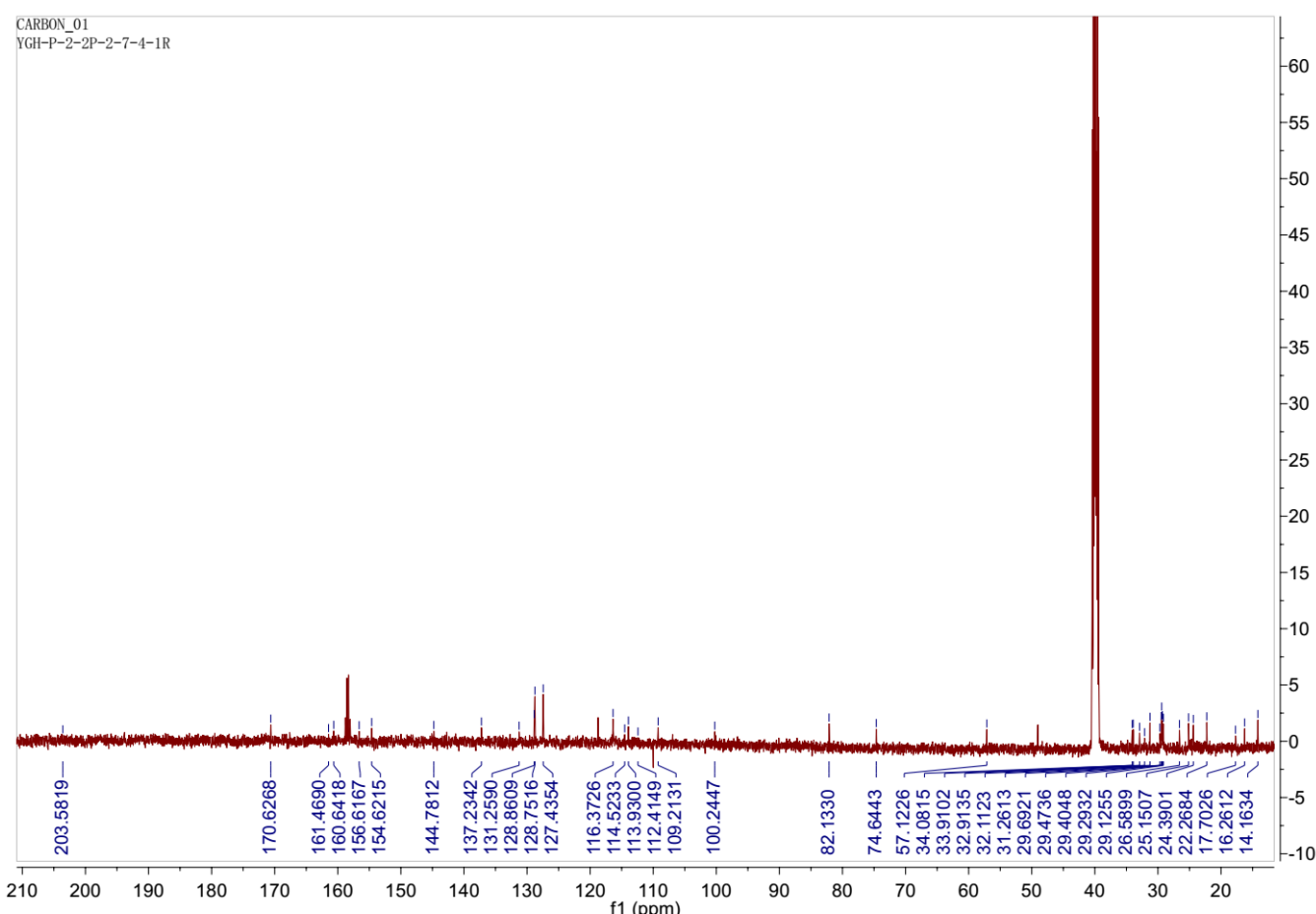

Figure S36. HSQC spectrum of 1a

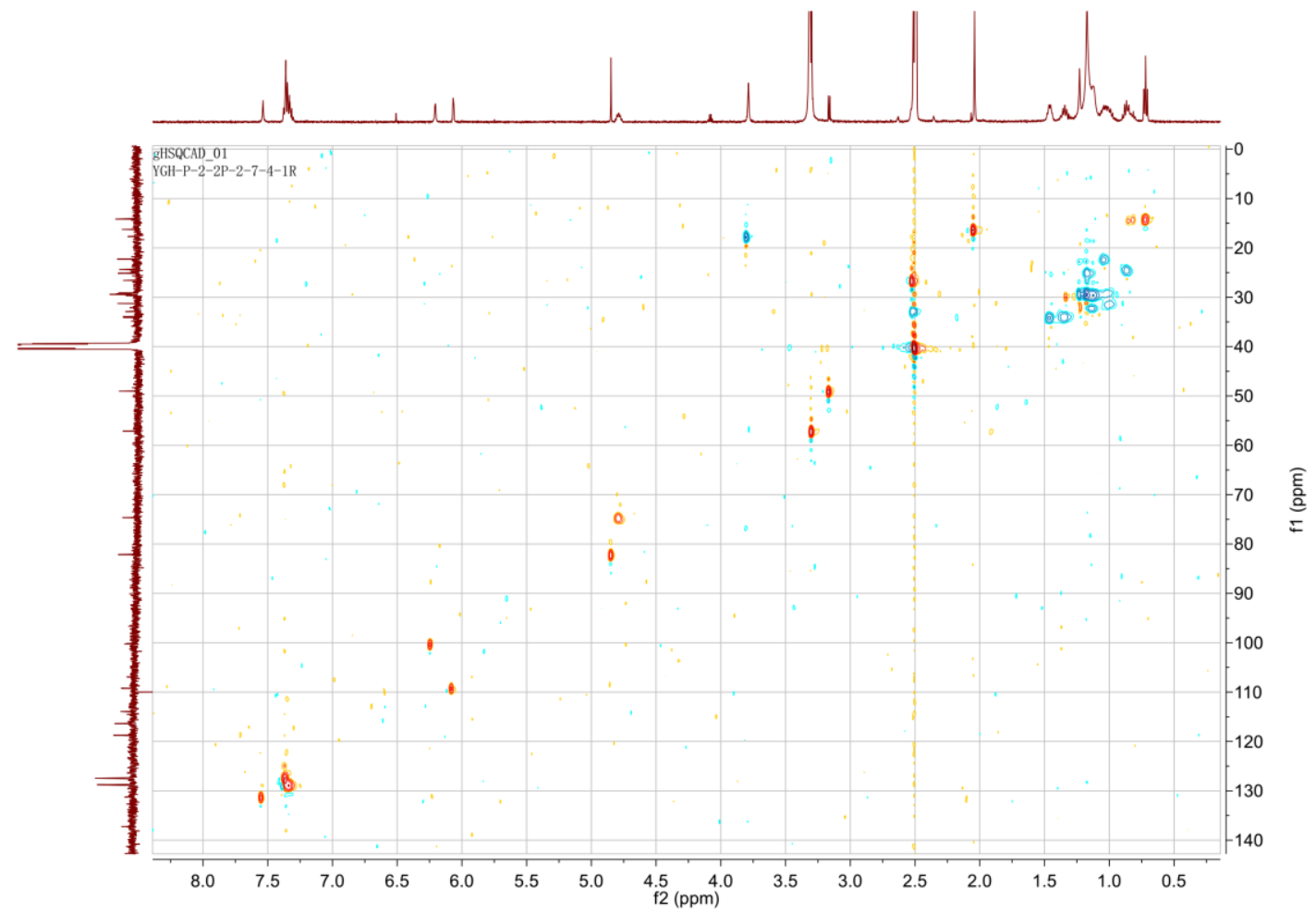


Figure S37. ${ }^{1} \mathrm{H}-{ }^{1} \mathrm{H}$ COSY spectrum of $\mathbf{1 a}$

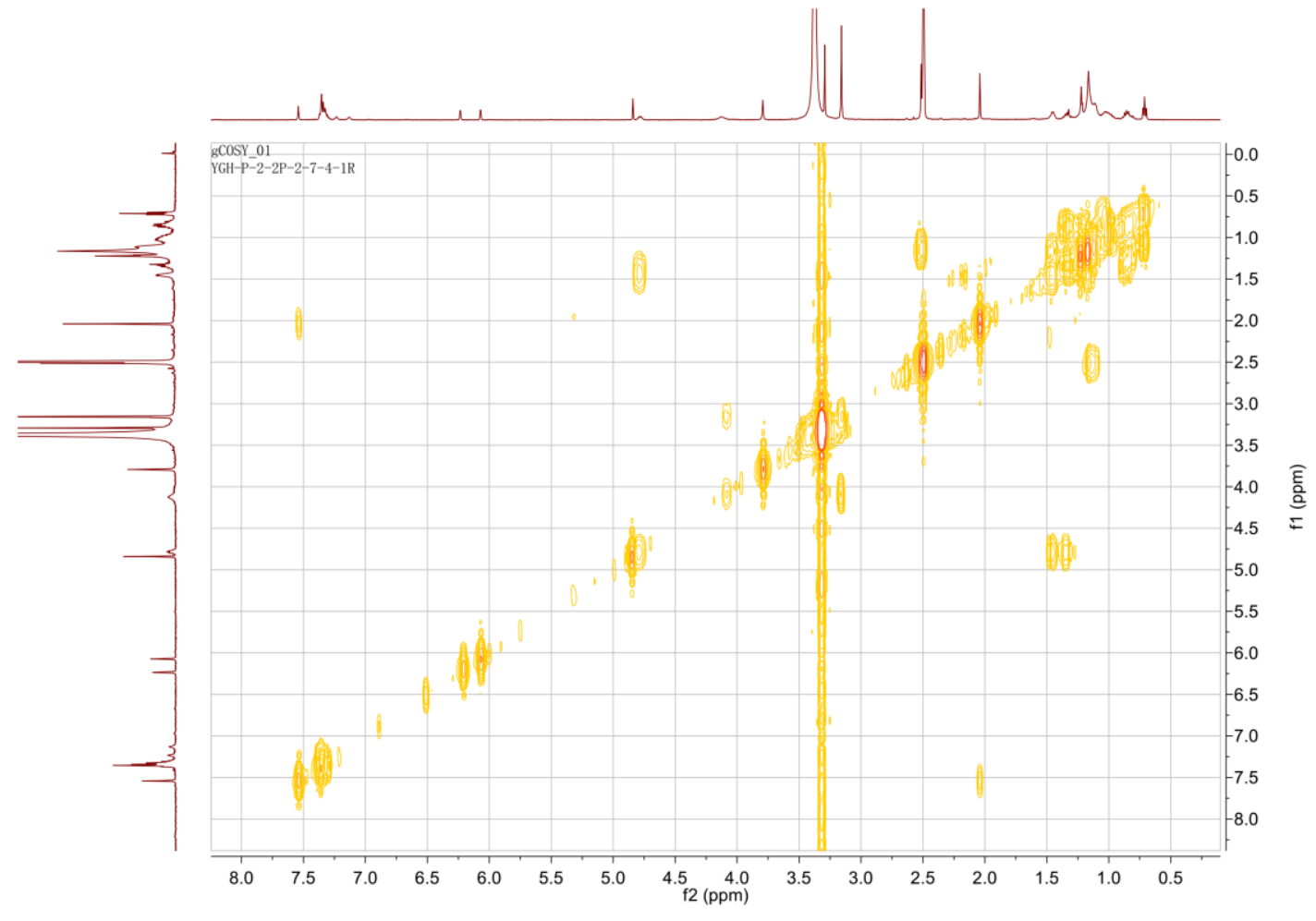

Figure S38. HMBC spectrum of 1a

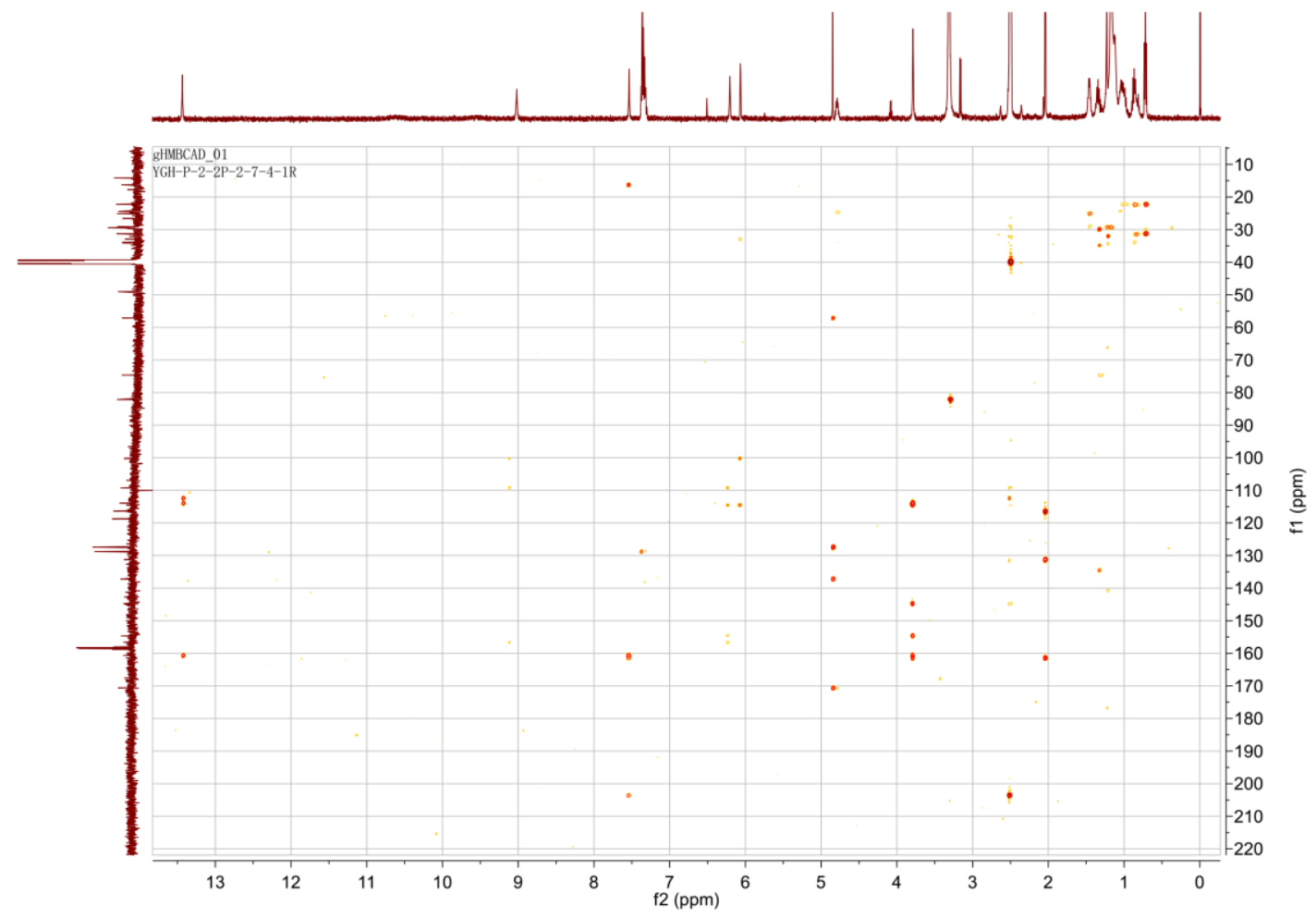


Figure S39. ${ }^{1} \mathrm{H}$ NMR spectrum $(500 \mathrm{MHz})$ of $\mathbf{1 b}$ in DMSO- $d_{6}$

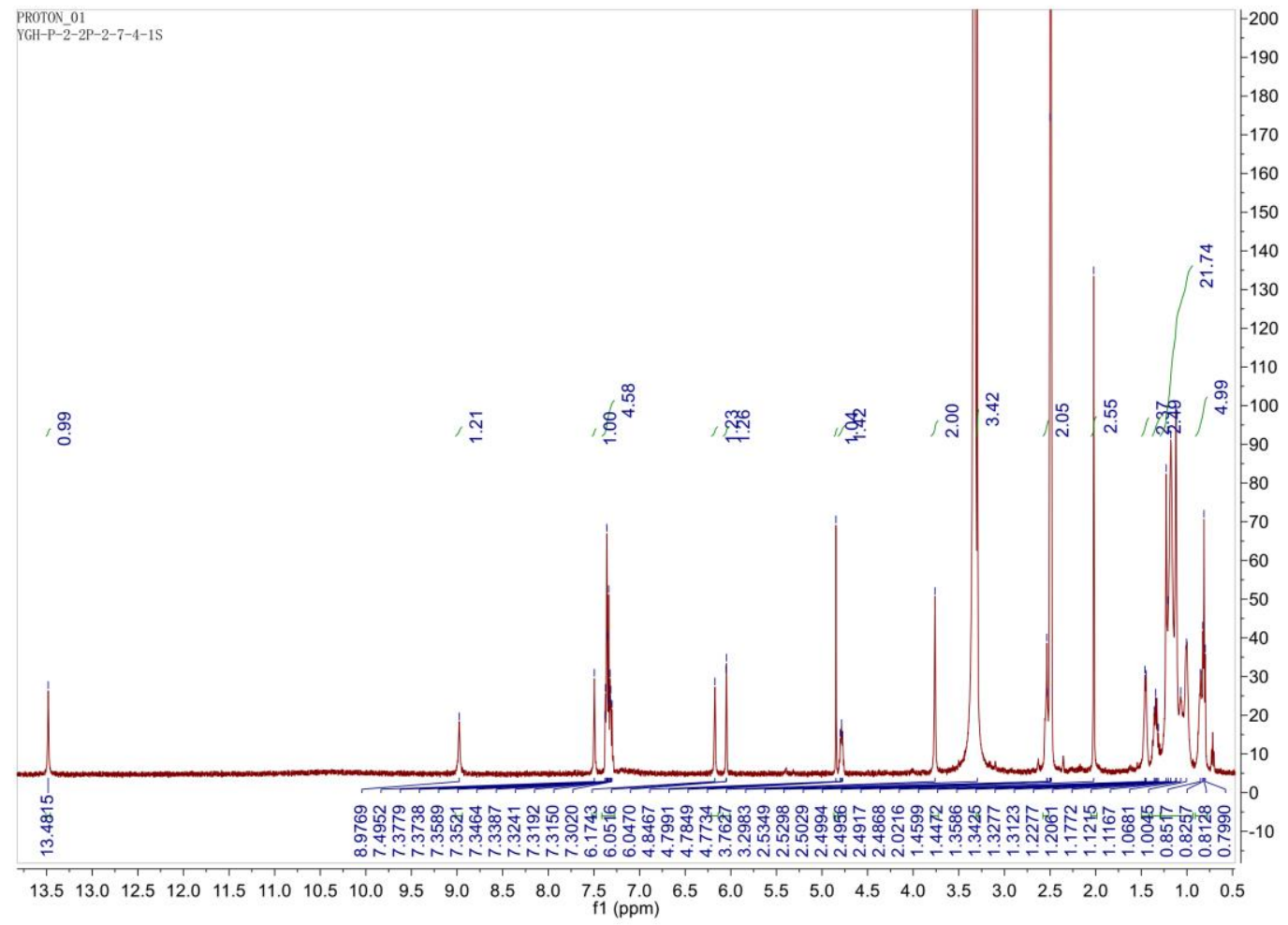

Figure S40. ${ }^{13} \mathrm{C}$ NMR spectrum (125 MHz) of $\mathbf{1 b}$ in DMSO- $d_{6}$

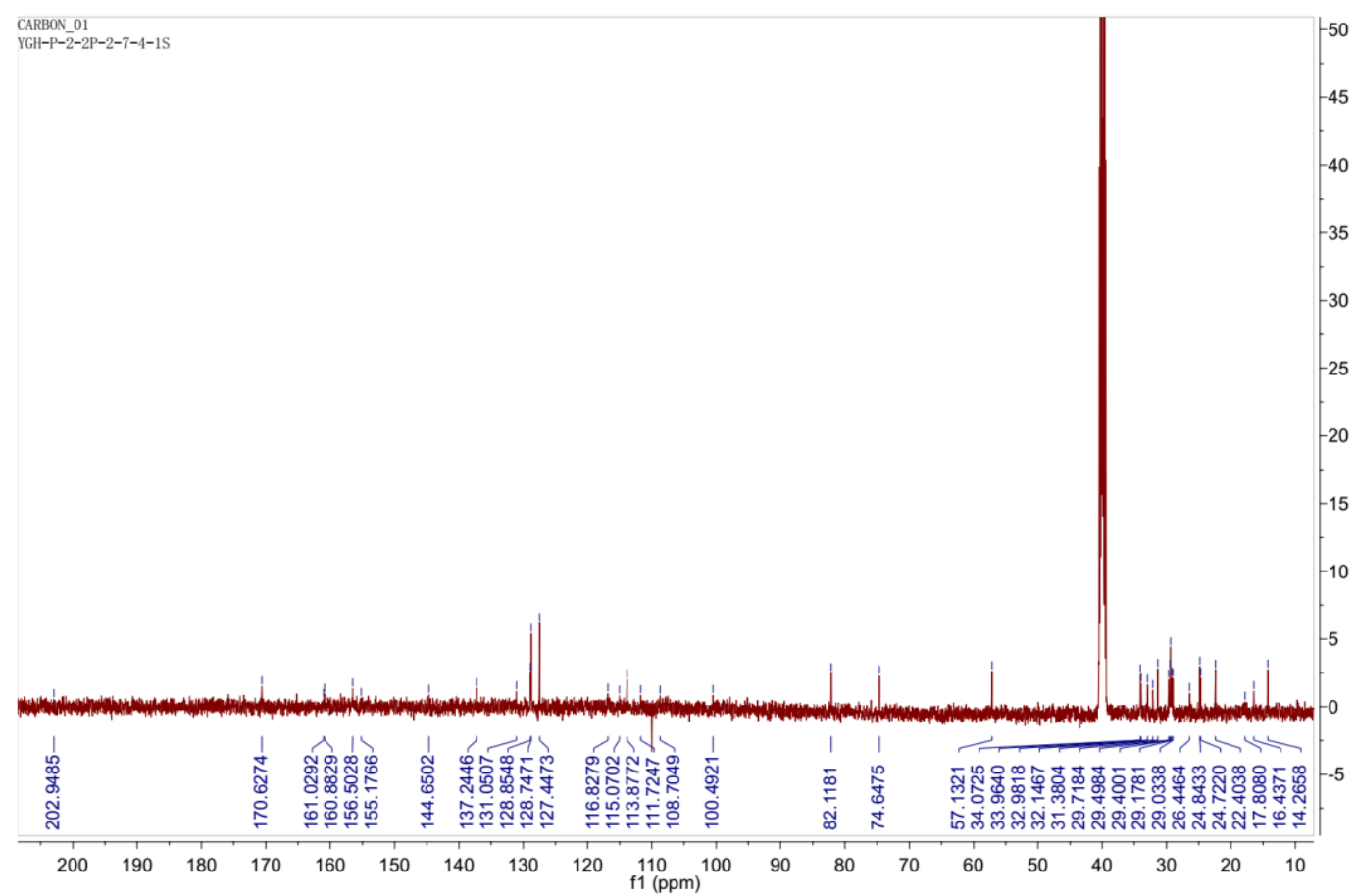


Figure S41. HSQC spectrum of $\mathbf{1 b}$

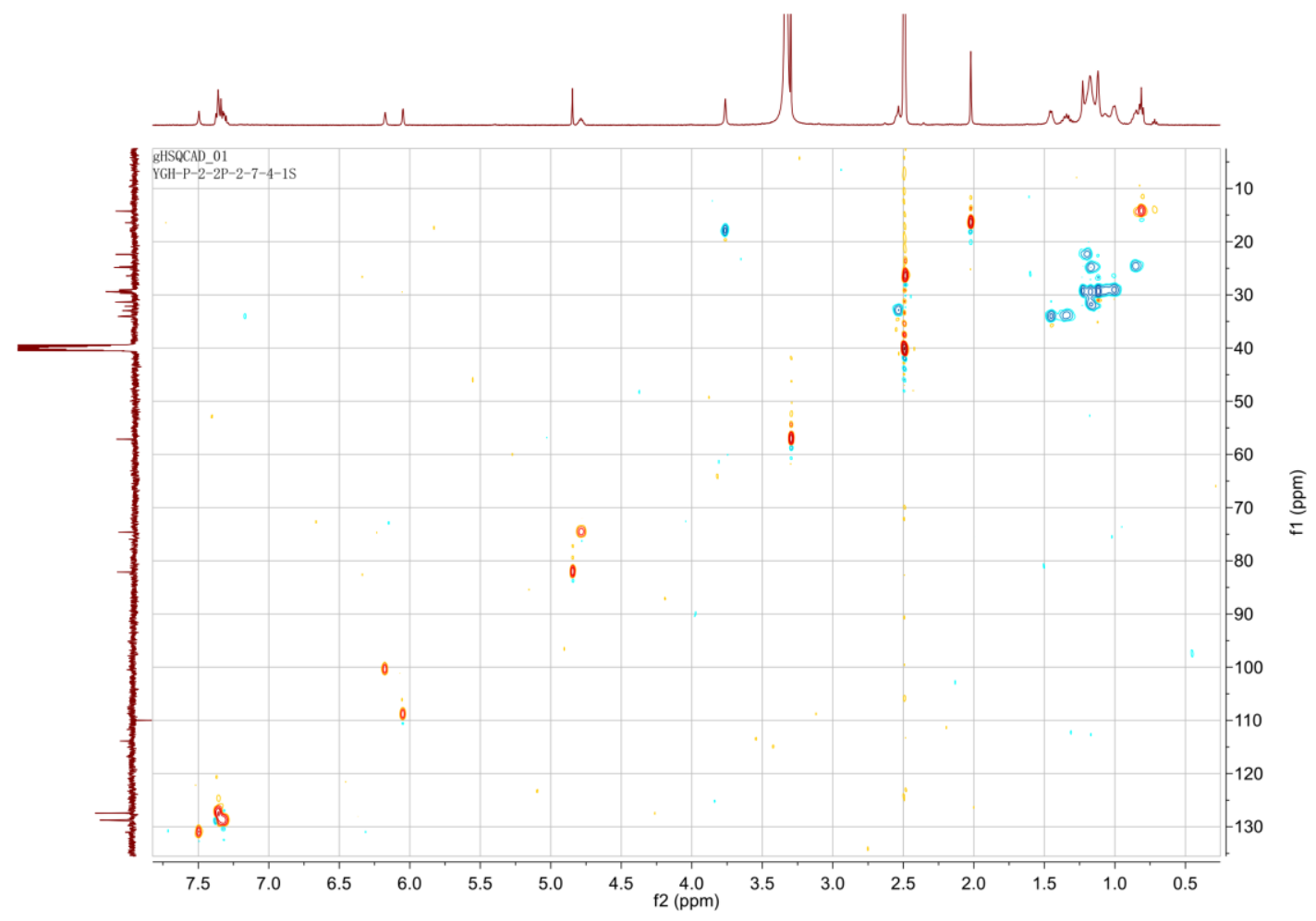

Figure S42. ${ }^{1} \mathrm{H}-{ }^{1} \mathrm{H}$ COSY spectrum of $\mathbf{1 b}$

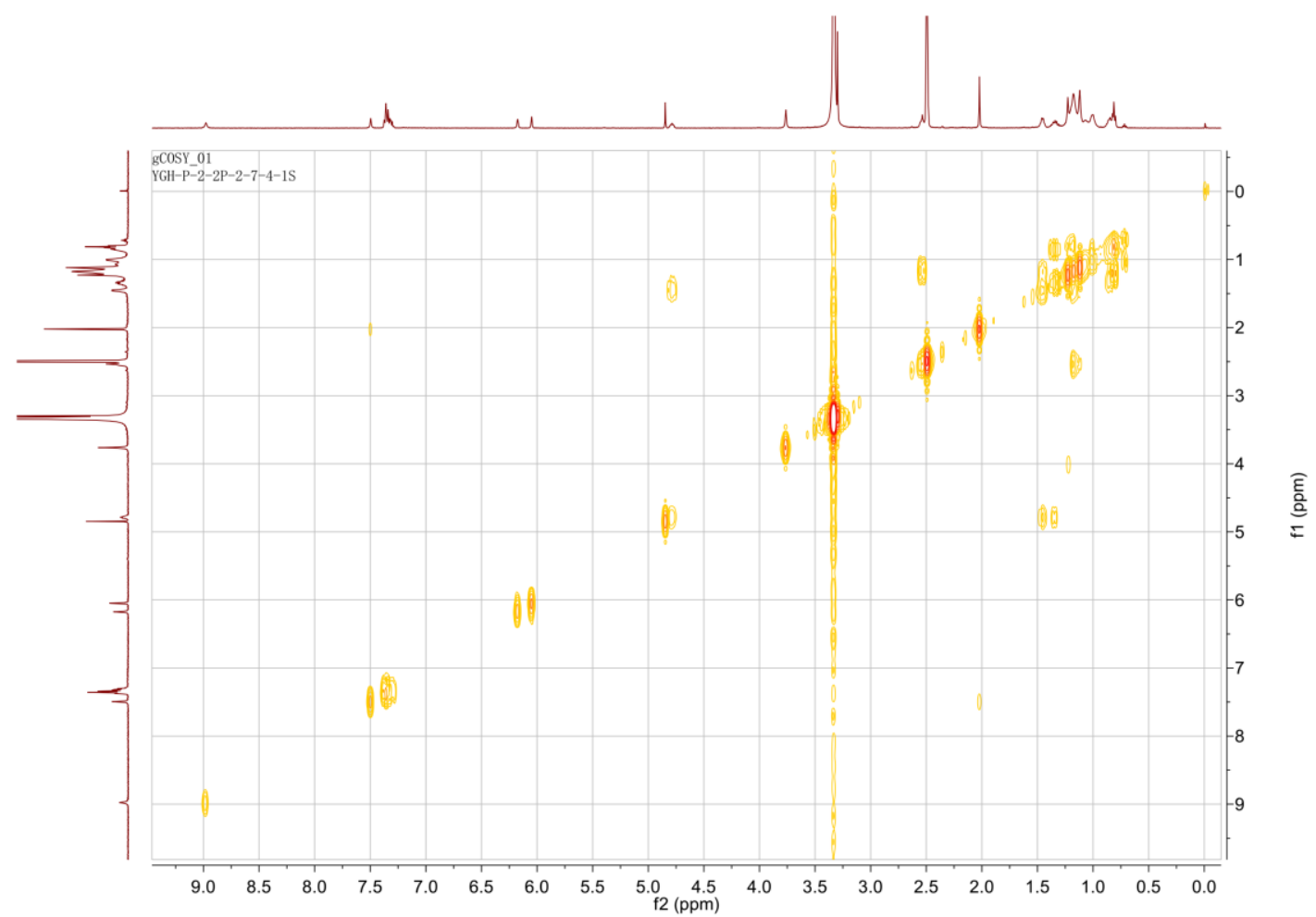


Figure S43. HMBC spectrum of $\mathbf{1 b}$

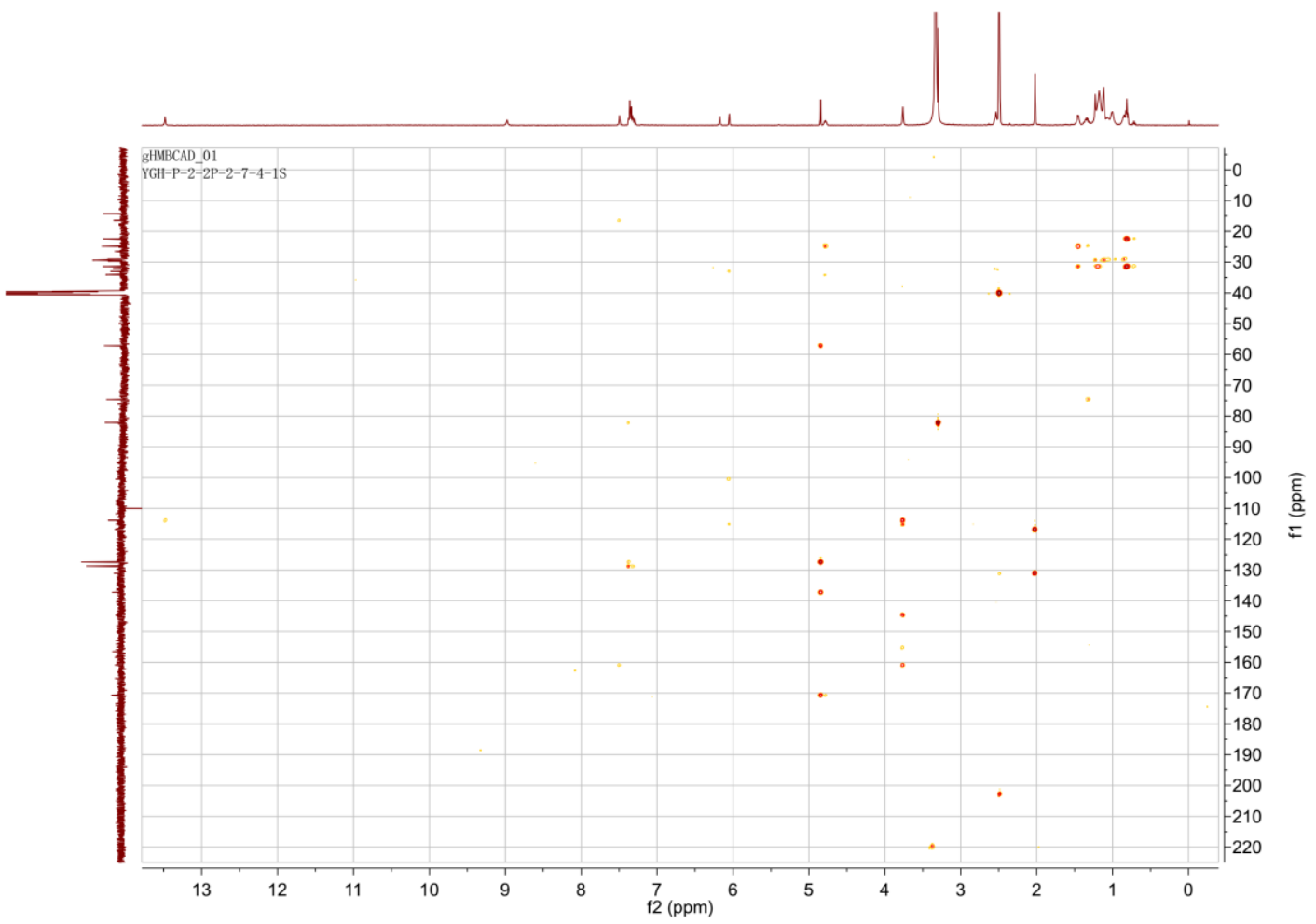

30 